\title{
Sagunto, el emporion de Arse, punto de fricción entre las políti- cas de Roma y Cartago en la península Ibérica.
}

\author{
Adolfo J. DOMÍNGUEZ MONEDERO \\ Universidad Autónoma de Madrid
}

\begin{abstract}
Resumen
El presente artículo intenta argumentar acerca de la dualidad de nombres que conocemos para Sagunto (ArseSaguntum); a partir de los testimonios existentes (literarios, arqueológicos, numismáticos) se defiende que el área situada en el Grau Vell, y que tenía carácter empórico, pudo haber sido ya denominada por los griegos Saigantha, siendo Arse el nombre de la comunidad política, tal y como atestigua la moneda. Analizando otros emporia conocidos se intenta mostrar cómo estos emporios pueden haber desarrollado una personalidad propia que puede haber influido en el desarrollo de la comunidad política de la que dependen. El problema de la intervención romana y del inicio de la Segunda Guerra Púnica se reintepreta a partir de estas perspectivas.
\end{abstract}

Palabras clave: Sagunto, Arse, emporion, Roma, Cartago.

\section{Summary}

This paper attempts to argue about the duality of names we know for Saguntum (Arse-Saguntum); from existing evidence (literary, archaeological, numismatic) it is argued that the area in the Grau Vell, which had an emporic character, could have been called by the Greeks Saigantha, Arse being the name of the political community, as evidenced by the coins. Analyzing other known emporia, we try to show how these emporic places may have developed their own personality and how they may have influenced the development of the political community to which they belong. The problem of Roman intervention and the start of the Second Punic War is reintepreted from these perspectives.

Keywords: Saguntum, Arse, emporion, Rome, Carthage.

\section{1.- INTRODUCCIÓN.}

El tema de los orígenes de la Segunda Guerra Púnica, desde el punto de vista de las responsabilidades, es algo que sigue aún sin resolverse debido sobre todo a las fuertes implicaciones que el tema tuvo ya para los autores antiguos para quienes una u otra actitud implicaba culpar o exonerar a Roma de iniciar una guerra injusta. No cabe duda alguna de que, dependiendo de los intereses y posturas de unos y otros, Roma, Aníbal o Cartago figuraban como causantes de este largo y sangriento conflicto. Es también cierto que los principales autores que tratan del tema, Polibio y Livio, presentan la visión de Roma y no es menos cierto que los autores que pudieran haber representado la visión de Cartago o de Aníbal no han llegado hasta nosotros más que de forma fragmentaria; todo ello hace complicado conocer sus argumentos que, en todo caso, y una vez que Roma hubo derrotado a Cartago, fueron descartados por el vencedor, cuya victoria sólo pudo haber sido conseguida por la justicia de su comportamiento, dentro de la lógica explicativa del bellum iustum.

No es, sin embargo, mi propósito aquí entrar en todas esas causas y motivos sino, tan solo, revisar la problemática que plantea el caso de Sagunto, bien conocida por haber sido el deto- 
nante o el pretexto, tal vez a su pesar, para el estallido de la Segunda Guerra Púnica; es por esta circunstancia por lo que las fuentes literarias dan bastantes datos sobre este centro aunque tampoco son del todo suficientes para aclarar su estatus y el porqué de su eventual importancia como desencadenante del conflicto.

\section{2.- El Tratado del Ebro y Sagunto.}

Aunque todo el asunto de Sagunto se intercala con el referido al tratado de Asdrúbal con los romanos (el "Tratado del Ebro") tampoco insistiremos demasiado aquí sobre este último, bien tratado, entre otros, por Scardigli ${ }^{1}$ que recoge buena parte de la literatura y de las diferentes posturas de la historiografía. Un intento de resolver las contradicciones de la tradición antigua fue considerar que el río Hiberus que habría sido objeto del tratado de Asdrúbal no era el actual Ebro sino el Júcar². Así, situando a Sagunto al norte del Hiberus se resolvían de modo definitivo todos los problemas que planteaba el ataque cartaginés a la misma, puesto que entonces, obviamente, Aníbal habría violado el tratado firmado por Asdrúbal. Es lástima que esta solución tan "evidente" no haya sido contemplada de forma clara por ningún autor antiguo, ni tan siquiera por los contemporáneos de Aníbal, en especial los romanos y prorromanos que lo habrían tenido muy fácil para exculpar a Roma $^{3}$. Los autores filocartagineses, entre ellos Sileno, Sósilo o Quereas habrían insistido en que el ataque a Sagunto no quebrantaba tratado alguno y hubiera sido difícil rebatirlos. Lo cierto es que todos los autores muestran su embarazo ante el ataque a Sagunto aunque por distintos motivos: para unos, y a pesar de estar situada al sur del Hiberus-Ebro, había que seguir justificando el porqué del ataque de Aníbal y para otros, y también a pesar de estar al sur del Hiberus-Ebro,

1 Scardigli, 1991: 245-296. Un estado de la cuestión, con la literatura posterior, puede verse en Loreto: 2011: 193-196 y Hoyos, 2011: 216-219.

2 El principal impulsor de esta teoría fue Carcopino, seguido por algunos otros. Vid. Carcopino, 1953: 258-293; Id., 1960: 341-346; una revisión bibliográfica y un apoyo a sus ideas en Jacob, 1988: 187-222. Otros autores, aunque aceptando esa teoría, prefieren el Segura al Júcar: Barceló, 2010: 407-416.

3 Aunque reconozcamos con Jacob, 1988: 187-222 que varios ríos fueron conocidos, en distintos momentos, con el nombre de Hiberus, resulta difícil seguir a este autor cuan- había que justificar por qué Roma la utiliza como casus belli; por ende, y como ha mostrado Scardigli, Polibio vincula el asunto de Sagunto al Tratado del Ebro, aunque en origen ambos temas no estaban relacionados, como mostraría el propio Polibio, mientras que otros autores, como Livio, están sólo preocupados por dar una visión coherente aunque ello implique sacrificar elementos que no encajen bien en el marco general ${ }^{4}$. El debate, pues, no se resuelve moviendo la ubicación del Hiberus sino analizando las circunstancias en las que se desenvuelve Sagunto a finales del s. III a.C.

Por otro lado, ya en las fuentes primarias, es decir aquellas que son contemporáneas de los hechos que narran, hay diferencias de criterio. Aparte de los autores filocartagineses cuyas obras hemos perdido y de los que es difícil detectar sus huellas en la tradición ulterior, entre los propios autores romanos y filorromanos hay algunas diferencias. Por ejemplo, es bien conocida la disparidad de criterios que mantienen Fabio Píctor (contemporáneo de los hechos) y Polibio sobre la implicación individual de Aníbal, o conjunta de Cartago, en el inicio de la guerra y la desautorización que hace Polibio del autor romano (Pol., III, 8-9), no siempre aceptada por la crítica contemporánea $^{5}$; por otro lado, parece fuera de dudas que Polibio ha contado, sobre todo el asunto, solo aquellos datos que le resultan de interés para adjudicar la responsabilidad de la guerra a Cartago, como muestran, por ejemplo, sus informaciones sobre el Tratado del Ebro, que no ha transmitido en su integridad, sino que ha hecho llegar a sus lectores solo aquella parte que le interesa ${ }^{6}$.

La propia relación de Sagunto con Roma no aparece denominada siempre del mismo modo en Polibio. Para este autor, los saguntinos estaban

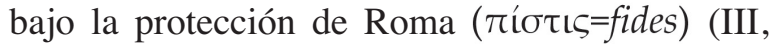

do asegura que Polibio no habría distinguido el HiberusEbro del Hiberus-Júcar éste último presuntamente redenominado no haría mucho con su nombre definitivo, Sucro.

4 Scardigli, 1991: 265-266. Como ha mostrado esta autora (ibid., 268) sólo tradiciones tardías hablan de relaciones de alianza entre Roma y Sagunto.

5 Brizzi, 2005: 33-34; Gelzer, 1933: 129-166; Levene, 2010: 160. Un análisis del texto en López Gregoris, 1996: $207-$ 231.

6 Scardigli, 1991: 272-273; vid. también sobre el asunto de las responsabilidades Wagner, 1984: 189-195. 
15, 5; III, 30, 1), a la que habían otorgado plenos poderes para resolver sus asuntos (Pol., III, 17, 7)

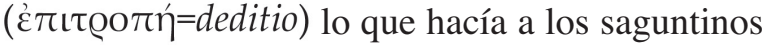
confiar en su alianza $(\sigma v \mu \mu \alpha \chi i \alpha=$ foedus) con los romanos (Pol., III, 15, 8); esa indefinición o esa modificación de la relación a lo largo del tiempo puede haberle resultado incómoda a Polibio, hasta el punto de llegar a utilizar fuentes que se equivocaban al situar Sagunto con relación al Ebro7.

Tampoco se sabe con certeza cuándo se habían iniciado las relaciones entre Sagunto y Roma más allá del genérico"muchos años antes de la época

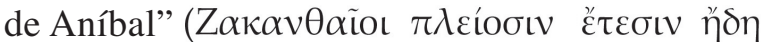

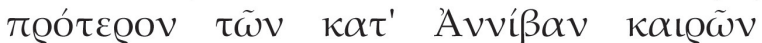

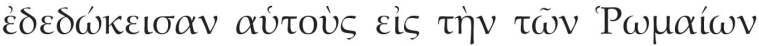

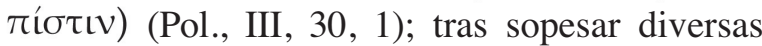
posibilidades, Scardigli se decanta por situar el inicio de estas relaciones en el periodo en torno al 224-3 a.C., en el momento en el que Roma se inmiscuye en los asuntos internos de Sagunto aun cuando en esos momentos ni Asdrúbal ni Aníbal pudieron intervenir dilatándose la respuesta cartaginesa unos años; Roma no intervenga durante el sitio de Sagunto por parte de Aníbal confirmaría que el acuerdo entre ambas ciudades no era de carácter jurídico lo que le impedía actuar legítimamente en el conflicto $^{9}$.

Esa fecha puede considerarse adecuada, frente a otras propuestas más altas ${ }^{10}$, que pierden de vista un hecho relevante. Una vez que parece descartarse de modo definitivo que la política de Amílcar le llevase hasta las costas orientales de la Península Ibérica, lo que permite rechazar tam-

7 Scardigli, 1991: 273-274; por otro lado, Beck, 2011: 231 sugiere que no deberíamos creer que la terminología usada delata una gran precisión formal en las relaciones internacionales romanas del periodo medio-republicano.

8 Scardigli, 1991: 274-275.

9 Scardigli, 1991: 277; sobre las intenciones hegemónicas de Roma, vid. Barceló, 1996: 45-57; igualmente, Hoyos, 2011: 220.

10 Así, por ejemplo, Eckstein, 1984: 51-68, que la sitúa entre 237 y 228 a.C. al ponerla en relación con los avances de Amílcar hacia la costa materializados en la fundación de Akra Leuke; recientemente, Loreto, 2011: 196, ha propuesto 228-227 a.C., fecha que nos sigue pareciendo demasiado alta.

11 Sumner, 1968: 209-210; Chic, 1978: 235-236. Últimamente se prefiere una ubicación en la Alta Andalucía: Wagner, 1999: 265-268; García-Bellido, 2000: 130-131 o, incluso, bién una ubicación costera para su fundación Akra Leuke (Diod., XXV, 10, 3) ${ }^{11}$, hay que considerar que es Asdrúbal quien marca una nueva orientación a la política cartaginesa en Iberia con la fundación de Cartago Nova entre el 230 y el 228 a.C. (Pol., II, 13, 1; Diod., XXV, 12) ${ }^{12}$. La fundación de esta ciudad, en una zona importante no sólo para el control de las minas de plata sino también desde el punto de vista de las relaciones comerciales entre diversos puntos de las costas peninsulares, Ibiza y el Norte de África marcaba de forma clara el deseo de los cartagineses de convertirse en actores activísimos en las transacciones comerciales en esta parte del Mediterráneo ${ }^{13}$; a ello se le unían claros intereses políticos y militares, requisito indispensable en esos momentos para conseguir tales objetivos ${ }^{14}$. No sabemos si anticipando lo que luego ocurrirá o recogiendo impresiones contemporáneas al hecho, Polibio (II, 13, 3) asegura que esa fundación significaba el surgimiento de un gran y terribilísi-

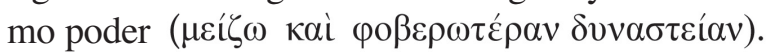

Esa nueva política implicaba, sin ninguna duda, el establecimiento de puntos de intercambio controlados, empezando por la propia Cartago Nova, que garantizasen la llegada de recursos económicos a la misma y, cómo no, a la metrópolis cartaginesa. La aparición en estos momentos de algunos centros fortificados de clara filiación cartaginesa como el Tossal de ManisesLucentum $^{15}$ muestra a las claras la nueva proyección política y económica que Asdrúbal quería dar a su fundación, mediante la construcción de fortalezas que crearan un círculo defensivo en torno a

en el entorno de la Baja Andalucía (Carmona): Bendala, 2010: 445-450. Vid. sin embargo, cómo todavía recientemente algún autor sigue proponiendo Alicante: Hoyos, 2003: 65

12 Sobre el panorama arqueológico de la fundación cartaginesa, vid. en último lugar Ramallo, S., Ruiz Valderas, 2009: 529-544; Ruiz Valderas, 2011: 50-55.

13 Una prueba de este papel la vemos en la arenga que Livio (XXVI, 43) pone en boca de Escipión en el momento previo a la toma de la ciudad por Roma en el 209 a.C.

14 Sobre los mecanismos comerciales de Cartago en la Península Ibérica, vid. Bendala, 1987: 153-155.

15 Olcina, 2002: 255-258; Id., 2009b: 40-41; sobre la muralla, las puertas, espacios domésticos y cisternas de la ciudad púnica, vid. Id., 2009a: 65-105; Olcina et al., 2010: 229249. 
su nueva capital y que protegieran los puntos clave de la ruta marítima al tiempo que sirvieran para drenar los recursos locales. Éste es el auténtico cambio que se produce en la Península y lo que marca una diferencia sustancial con respecto a lo que había sido la política de Amílcar, más interesada en el control del valle del Guadalquivir y de los territorios de la Alta Andalucía, como base imprescindible para garantizar, con la salida al mar que llevará a cabo su yerno Asdrúbal, un área de control efectivo que, por la presión romana, se aceptará limitar por su extremo septentrional en el río Hiberus-Ebro; Diodoro (XXV, 12), además, asegura que Asdrúbal fundó una ciudad más cuyo nombre no da, con el deseo de superar

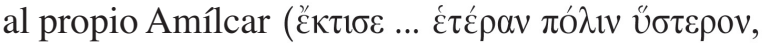

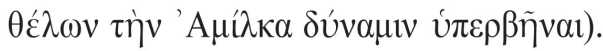

Ante este panorama, marcado como decíamos por el establecimiento de puntos de control costero fortificados, como Lucentum, que podían servir también de puntos avanzados de cara a actividades en áreas más alejadas, algunos centros preexistentes pudieron haberse sentido amenazados y es posible que, entre ellos, estuviese Sagunto o, al menos, una parte de quienes tenían a este punto como base de operaciones. Por supuesto, una flota de guerra con base en el excelente puerto de la nueva ciudad, y que ya se menciona en el momento en el que Aníbal transfiere el mando de Hispania a su hermano Asdrúbal (Pol., III, 33, 14; Liv., XXI, 22,4) se encargaría de asegurar el control cartaginés sobre los territorios costeros.

La respuesta romana a la fundación de Cartago Nova es, sin duda ninguna, el "Tratado del Ebro", que sólo tiene sentido cuando Asdrúbal ha dejado clara la intención de Cartago de hacerse presente en las regiones costeras del este de la Península; la embajada romana del 231 ante Amílcar (Dio. Cass., XII, 48) si es que de verdad existió ${ }^{16}$ presupone un desconocimiento total de lo que estaba haciendo Cartago en Iberia, en buena parte porque aún sus intereses no afectaban a las regiones costeras, sobre las que podían estar mejor informados gracias a sus aliados por lo que resulta difícil que, en esos momentos, Sagunto hubiese estado en la agenda de los embajadores romanos ${ }^{17}$.

\footnotetext{
16 Sumner, 1968: 205-208; $c f$. Hoyos, 2003: 61, que tiende a no creer dicha embajada.

17 Frente a lo que pensaba Eckstein, 1984: 56, para quien esta
}

En cualquier caso, tampoco me parece probable que Roma aceptase la alianza o la sumisión de Sagunto con motivo del "Tratado del Ebro" que, como ya vimos antes, tampoco tuvo una virtualidad jurídica clara. Da más la impresión, por el contrario, de que una vez definidas no tanto las áreas de influencia sino, porque es lo que dice el tratado, los límites que no deberían sobrepasar los car-

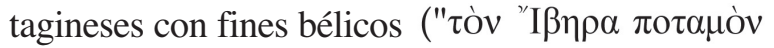

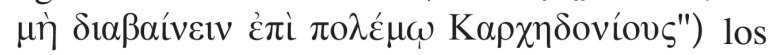
que habían quedado incluidos, quisiesen o no, dentro del área cartaginesa hiciesen movimientos para lograr la implicación romana. A ello, sin ninguna duda, se refiere Polibio cuando hace un largo y algo confuso comentario a los pactos establecidos con Asdrúbal (el "Tratado del Ebro") al que añade datos tomados del tratado de Lutacio Catulo con relación a los aliados: "Y en los tratados sobre Sicilia se hallaba escrito, tal y como dicen también aquellos, 'que se garantice a los aliados de ambos seguridad entre cada uno de los dos', no sólo a los que entonces eran aliados, tal y como hacían la interpretación los cartagineses. De haber sido así se habría añadido que no se aceptasen otros aliados junto a los existentes o que a los que fuesen aceptados posteriormente no se les incluyese en los tratados. Pero como ninguna de las dos cosas se escribió, era patente que a todos los aliados de las dos partes, tanto a los que ya lo eran como también a los que fuesen incluidos después de eso, se les daría siempre la misma seguridad entre ambos que a los que ya lo eran. Todo ello parecería sin duda razonable. Ciertamente que no se habrían realizado tratados tales que hubieran impedido la posibilidad de recibir a otros según las circunstancias, si hubiera sido conveniente, como amigos y aliados o que les forzaran a abandonar a los que mantenían en su alianza tras haber recibido injusticias por parte de algunos; pero lo esencial del pensamiento de las dos partes en los tratados era no osar tocar a los que entonces eran aliados de cada una de las partes y de ningún modo aceptar en alianza a cualquiera que fuese aliado de los otros" (Pol., III, 29, 4-9; traducción de M. Balasch; $c f$. Liv., XXI, 19, 5).

embajada habría sido la ocasión propicia para que Roma hubiese entrado en contacto con Sagunto. 
Que todo ello es importante para Polibio se demuestra cuando culpa a los cartagineses de iniciar la guerra, ya sea contraviniendo el tratado de Lutacio Catulo ya el de Asdrúbal (Pol., III, 30, 3) cuando ambos tratados se referían a asuntos y a territorios distintos. La discusión recién mencionada y la asignación de culpas a partir de tratados que parecen tener poca relación directa entre sí lo que muestra es que los argumentos no estaban demasiado claros incluso para un autor filorromano como Polibio y había que aducir todo aquello que se tuviera a mano para justificarlo ${ }^{18}$. Polibio interpreta que los nuevos aliados de cada parte recibirían el mismo trato que los que ya lo eran cuando se firmó el tratado de Lutacio Catulo y da a entender que eso mismo se aplicaría en el Tratado del Ebro, pero eso es una interpretación de Polibio que asegura, antes de su larga disquisición, que éstas fueron las razones que justificaban la actuación romana, aunque las mismas "no se manifestaron entonces a causa de la rabia causada por la destrucción de Sagunto" (Pol., III, 29, 1). Lo que indica eso es que en el momento de la guerra esos argumentos no se habían tenido en cuenta y habían sido desarrollados a posteriori, sin que tampoco podamos descartar que el propio Polibio haya intervenido en la introducción en el debate de viejos tratados que nada tenían que ver con el asunto para justificar la acción romana.

Porque la clave de todo el asunto está, como bien se puede entender, en la alianza de Roma con Sagunto y, sobre todo, en cuándo se produjo ésta ${ }^{19}$. Pero, aun cuando no quede claro, como hemos visto antes, si había una alianza auténtica entre Roma y Sagunto ni tampoco desde cuándo podía haber existido ésta, el argumento de Polibio es que incluso a los nuevos aliados les asisten los mismos derechos que a los aliados antiguos. Si esto es así, esta retroactividad que Roma (o Polibio) quieren aplicar a Sagunto que no era aliada de Roma en el momento de la firma del tratado de Lutacio Catulo y de la que seguramente no se hablaba en el "Tratado del Ebro" no es sino un reconocimiento de que el caso de la ciudad hispana no figuraba de modo explícito en ningún trata-

18 Quizá Serrati 2006: 133-134, aun reconociendo en Polibio "an instrument of Roman imperialism", sea demasiado benévolo al exonerarle en esta cuestión, admitiendo, como mucho, que el megalopolitano no pudo averiguar cuándo se había producido con exactitud la alianza entre Roma y Sagunto. do previo y con la interpretación de Polibio se justifica el derecho de los romanos a recibir como aliados suyos a quienes en cada momento les interese; esta interpretación de Polibio presupondría que Sagunto no era tampoco aliada o súbdita de Cartago aunque ésta vería mal que Roma se aliase con una ciudad que, al estar situada al sur del Ebro, quedaba dentro del territorio en el que podía hacer uso, si así lo deseaba, de su ejército aunque se abstuviera de hacerlo durante algunos años (Pol., III, 14, 10) ${ }^{20}$.

Ecos de este debate lo encontramos también en Livio a propósito de la embajada romana compuesta por Q. Fabio, M. Livio, L. Emilio, G. Licinio y Q. Bebio y que llegó a Cartago en el 218 para inquirir de los cartagineses si Aníbal había atacado a Sagunto como consecuencia de una decisión pública (publico consilio) y, en caso afirmativo, declarar la guerra a Cartago (Liv., XXI, 18, 2). La respuesta cartaginesa presenta lo que puede haber sido la postura de Cartago, puesto que coincide con lo que relata Polibio aunque éste lo utiliza para darle una interpretación acorde con los intereses romanos: "Yo, en cambio, creo que se debería preguntar no si se atacó a Sagunto por decisión pública o privada, sino si se hizo justa o injustamente ... con vosotros solo cabe discutir si era legal hacerlo según el tratado. Así pues, dado que os place diferenciar lo que hacen vuestros generales por decisión pública de lo que hacen por su propia voluntad, nosotros tenemos con vosotros un tratado firmado por el cónsul G. Lutacio, en el que se tomaron decisiones sobre los aliados de ambas partes, pero nada sobre los saguntinos - en realidad todavía no eran aliados-. Pero en el tratado que se firmó con Asdrúbal no se tuvo en cuenta a los saguntinos" (Liv., XXI, 18, 69; traducción de A. Ramírez de Verger). Según el propio relato de Livio, los romanos no entran en la discusión y se limitan a ofrecer la paz o la guerra (Liv., XXI, 18, 13-14).

Más adelante, Livio, comentando el episodio alaba la actitud romana porque se ajustaba más a la dignidad del pueblo romano que "malgastar palabras sobre la legalidad de los tratados" (magis

19 Vid. Sancho, 1976: 96-106.

20 Vid. una discusión reciente en Hoyos, 2011: 216-219, que concluye que "Saguntum was probably not an ally at all, yet Rome, while refusing to admit this, was treating it like one". 
ex dignitate populi Romani uisa est quam de foederum iure uerbis disceptare) (Liv., XXI, 19, 1), lo cual no deja de sorprender en un romano, tan atento a la literalidad de los acuerdos. Entra Livio, no obstante, en la discusión de los tratados, el de Lutacio y el de Asdrúbal y retoma, aunque con más brevedad, el mismo debate de Polibio sobre si se incluía a los aliados nuevos o no. Pero, sin duda, el último párrafo de su análisis es de gran interés; tras aceptar que los tratados no se oponían a la inclusión de nuevos aliados, afirma: "y dado que era legal aceptar nuevos aliados, ¿quién iba a considerar justo no aceptar a ningún pueblo como amigo por muchos méritos que tuvieran o no defenderlos después de haberlos recibido bajo su protección, con la sola excepción de que no incitaran a la defección a los aliados de los cartagineses ni recibieran a quienes habían hecho defección por su propia voluntad?" (Liv., XXI, 19, 5). Lo que Livio nos está diciendo es que, según la interpretación romana, los últimos pactos firmados entre Roma y Cartago no impedían nuevas alianzas y que, si éstas se producían, quedaban amparadas por los pactos firmados aunque los mismos hubieran tenido como objetivo resolver otros problemas. Sin duda ninguna, tanto Polibio como Livio están justificando la inclusión de Sagunto en la alianza con Roma aprovechando el silencio del Tratado del Ebro y haciendo uso de una interpretación muy cuestionable del tratado de Lutacio Catulo que, hay que insistir, no se refería en absoluto a la Península Ibérica, como el propio Polibio asegura, además de decir que en la sesión del senado cartaginés ante la que hablaron los embajadores romanos "leyeron muchas veces los tra-

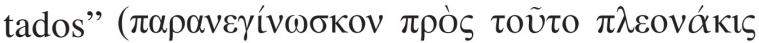

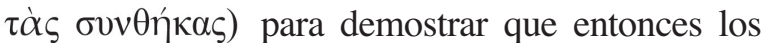
saguntinos no eran aliados de los romanos (Pol., III, 21, 3-5).

Lo que parece claro de todo esto es que en ninguno de los últimos tratados romano-cartagineses se había mencionado a Sagunto pero, a pesar de ello, los romanos reivindicaban su derecho a aliarse con quienes quisieran respetando tan solo algunas salvaguardas $\mathrm{y}$, una vez concluida la alianza, consideraban a los nuevos aliados protegidos por las mismas cláusulas que protegían a los aliados antiguos. Como para los romanos esta retroactividad era justa aunque no estuviera contemplada en los tratados, la defendían mediante una lectura amplia e interesada de los mismos que pretendían imponer a la otra parte. Esta visión romana, que no parece haber sido la inicial, acabaría imponiéndose cuando los romanos no consiguen que Cartago culpabilice a Aníbal que, para Fabio Píctor, como vimos, era el responsable auténtico, y no Cartago, a pesar de la división en Cartago y de los enemigos que el general tiene en su propia ciudad, encabezados por Hanón (Liv., XXI, 10). De ahí la petición de aclaración que los embajadores romanos llevan a Cartago pidiendo a su senado que aclarase si Aníbal actuó por su propia cuenta o por decisión del estado.

Es, pues, el momento de volver sobre cómo y cuándo se produjo la alianza de Roma con Sagunto.

\section{3.- LA ENTRAda de SAgunto EN LA ALIAN- ZA CON ROMA.}

No parece haber demasiadas dudas de que la intervención romana en los asuntos de Sagunto se produjo de forma intempestiva al aceptar, a petición de uno de los grupos enfrentados, intervenir en los asuntos internos de la ciudad. Polibio nos dice que, ante los embajadores romanos presentes en Cartago Nova, que habían atendido las continuas peticiones saguntinas (Pol., III, 15, 1), Aníbal acusó a los romanos "como si fuera él el encargado de velar por los saguntinos, de que aprovechando una revuelta que había estallado en

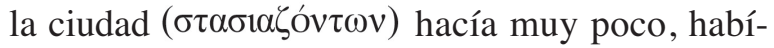
an efectuado un arbitraje para dirimir aquella turbulencia y habían mandado ejecutar injustamente

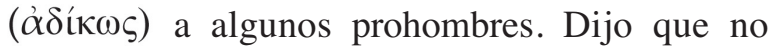
vería con indiferencia a los que habían sido traicionados. Pues era algo innato en los cartagineses no pasar por alto ninguna injusticia" (Pol., III, 15, 7).

La información de Polibio es muy parca y no nos permite saber ni quiénes se enfrentan ni por qué y si cada una de las dos partes en conflicto había llamado en su ayuda, respectivamente, a Roma y a Cartago, aunque veremos qué datos podemos extraer. En primer lugar, el conflicto es de tipo interno, entre miembros de la comu-

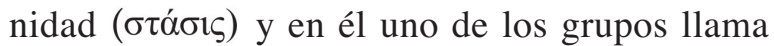
en su ayuda a los romanos quizá porque el otro cuenta con el respaldo de Cartago. Roma recibe plenos poderes para actuar, que es el mejor sen-

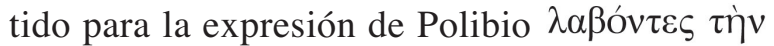

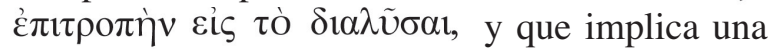


cesión de soberanía hacia Roma (una deditio in fidem); esta autoridad se la otorgarían los que pro-

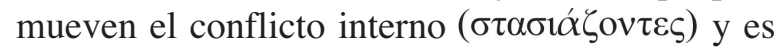
lo que justifica la actuación romana que consistió en ejecutar a algunos de los dirigentes de la ciu-

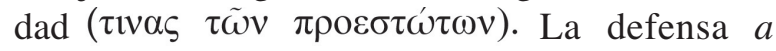
posteriori que hace Aníbal podría sugerir que estos notables eran pro-cartagineses al considerar que su ejecución y la intervención romana eran injustas aunque puede ser tan solo un recurso para justificar unas relaciones previas entre las autoridades de Sagunto y Cartago que quedarían de este modo atestiguadas.

Es posible que podamos obtener algún dato adicional de un autor de calidad muy inferior a nuestras dos principales fuentes, como es Apiano. Al narrar los prolegómenos del Tratado del Ebro, este autor asegura que "los saguntinos, colonos

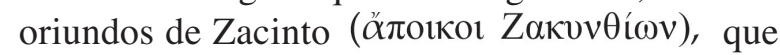
viven a mitad de camino entre los Pirineos y el río Ebro y todos los restantes griegos que habitaban en las proximidades del llamado Emporion y en cualquier otro lugar de Iberia, temiendo por su seguridad personal, enviaron embajadores a Roma ... Ambos llegaron al acuerdo de que el río Ebro fuera el límite del imperio cartaginés en Iberia ... y que los saguntinos y demás griegos de Iberia fueran libres y autónomos. Estos acuerdos fueron añadidos a los tratados ya existentes entre romanos y cartagineses" (App., Ib., 7, traducción de A. Sancho; $c f$. Han., 2). Además de la confusión sobre la ubicación de Sagunto con respecto al Ebro, la tradición que representa Apiano añade, quizá porque muchas fuentes analísticas lo habían incluido, la cláusula que ni tan siquiera mencionan Polibio o Livio que hacía a los saguntinos y a los demás griegos libres y autónomos y asegura que la misma se añadió a los tratados existentes, algo que también desmienten los otros dos autores ${ }^{21}$.

La referencia a la procedencia griega de los saguntinos ${ }^{22}$ se corresponde, como veremos, con la visión de los romanos y de los griegos y Apiano nos muestra en su texto huellas de parte de la justificación que los romanos acabarían dando para su intervención en los asuntos hispanos, a saber la protección de los griegos. Si se puede enlazar esta información con la que daba Polibio sobre la

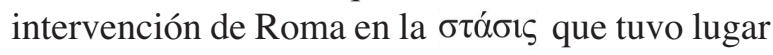
en Sagunto, ¿podríamos pensar que los griegos residentes en (alguna parte del territorio de) Sagunto, ante la fundación de Cartago Nova, hubieran podido presionar, dentro incluso de la ciudad ibera, para facilitar la alianza con Roma?. ¿Pudo eso haber provocado un conflicto interno dentro de la ciudad entre partidarios de esa decisión y los contrarios?. ¿La llamada a los romanos y la drástica intervención de éstos habría que entenderla como la imposición de una nueva orientación en la ciudad?. Estas preguntas, por desgracia, no tienen una respuesta clara ante la escasez de datos de nuestras fuentes pero, en todo caso, sí que podemos estar bastante seguros de que la consolidación del dominio cartaginés en las costas del Sudeste de Iberia con la fundación de Cartago Nova introdujo un nuevo elemento que quizá muchos no percibieran como negativo pero que para otros podía ser amenazador.

Hacía ya bastante tiempo que las grandes potencias tenían tendencia a arrogarse el control de las que consideraban sus áreas de interés económico y las relaciones entre Cartago y Roma, ya desde el final del s. VI a.C. y, sobre todo, a raíz del tratado romano-cartaginés del 348 a.C., se estaban desarrollando desde la perspectiva del control de las transacciones comerciales estableciendo zonas de exclusión, total o parcial, en aquellos territorios a los que sus ejércitos o sus flotas pudieran llegar ${ }^{23}$. Este hecho era, sin duda, bien conocido por todos los que se dedicaban al comercio en el Mediterráneo y, de este modo, no sería extraño que los centros comerciales o emporia que podían verse afectados por una política de control reaccionasen buscando apoyos que les permitiesen contrarrestar el mismo. Creo que es en este contexto en el que habría que situar la

21 En todo caso, puede ser un añadido a posteriori, del tipo del que encontramos en Livio (XXI, 2, 7), cuando al mencionar el tratado introduce a Sagunto "situado entre los imperios de ambos pueblos" (Saguntinisque mediis inter imperia duorum populorum) y de la que se dice que "conservaria su libertad" (libertas seruaretur), todo ello para culpabilizar a Aníbal y a Cartago: vid. Sancho, 1976: 107-110.

22 La mayor parte de los autores que tratan de los orígenes de Sagunto aluden, de una u otra forma a sus orígenes total o parcialmente griegos: Liv., XXI, 7, 2; Str., III, 4,6; Sil. It., Pun., I, 271-295; App., Ib., 25, Hann., 6; Plin., NH, XVI, 216).

23 Sobre el origen de este proceso vid. Domínguez Monedero, 2009: 127-146. 
petición de ayuda a los romanos por una parte de la población saguntina y la expeditiva respuesta romana no respaldada por ningún tratado por más que los romanos y, sobre todo los autores prorromanos, se esfuercen en intentar demostrarlo.

Antes de proseguir en la línea que hemos abierto conviene, sin embargo, decir algo sobre Sagunto.

\section{4.- ArSe-Saguntum: CIUDAd y EMPORION.}

Aun cuando puede que la referencia literaria más antigua en latín al nombre Sagunto sea la de Catón (De Agr., X) para quien el nombre del sitio sería Sacont $(i) u^{24}$, es también cierto que hubo una amplia variabilidad en la transcripción latina de ese término (Segontia, Seguntia, Sagontius, Saguntium, Saguntum, etc.). En griego, sin embar-

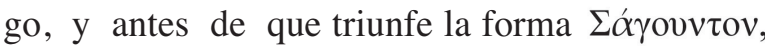
transcrita del latín Saguntum, el nombre habitual es Záкav $\theta \alpha$, como muestra siempre Polibio (passim). Aun cuando luego hablaremos de la tradición griega (y luego también romana por influencia de aquella) del origen de sus habitantes en Zacinto (Ź́кvv $\theta$ os), el hallazgo del llamado plomo de Ampurias ${ }^{25}$ muestra, a pesar de que aun hoy día no todo el mundo acaba por aceptarlo ${ }^{26}$, un tem-

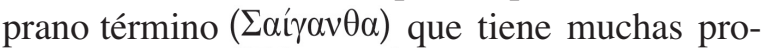
babilidades de haber sido el primer topónimo dado por los griegos a Sagunto ${ }^{27}$, que acabaría siendo adaptado, quizá por la literatura, para servir de vehículo a la tradición del origen griego del lugar, tan útil para unos y para otros para justificar sus actuaciones políticas en los años 219-218 a.C. Ya García y Bellido había sugerido, mucho antes de aparecer el plomo de Ampurias que "Saguntum, o un nombre ibérico semejante, pudo

24 Así, al menos, lo asegura Jacob, 1988: 204.

25 Sanmartí, Santiago 1987; 119-127; Santiago, Sanmartí, 1988: 100-102; Santiago, 1990a: 79-80.

26 Por ejemplo, y por citar sólo trabajos recientes, Aranegui, Vives-Ferrándiz, 2006: 98, nota 4; De Hoz, 2010: 647.

27 Santiago, 1990b: 123-140.

28 García y Bellido, 1948: II, 62.

29 Velaza, 2002: 139; Garcia-Bellido, Blázquez, 2002: II, 37-45.

30 Gozalbes, Ripollès, 2002: 217-227.

31 Además de destacarse que esta primera acuñación pudo haber puesto en circulación "una importante cantidad de monedas", se ha sugerido, incluso, que el grabador de alguno de esos primeros cuños pudo haber llegado de algún centro de Sicilia o la Magna Grecia: Ripollès, Llorens, 2002: 183-184. recordar a los historiadores helenísticos el de Zákynthos, y de ello pudieron hacer una leyenda como con frecuencia acaeció en muchos otros

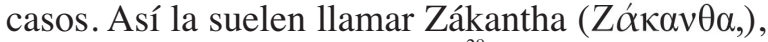
y de otros modos semejantes"

Por otro lado, entre las más antiguas acuñaciones de moneda indígena aparece la leyenda monetal Arse con distintas variantes que no cabe duda de que acabará identificándose con Sagunto como muestran las monedas bilingües ya en pleno periodo romano ${ }^{29}$. Según parece, y aunque ya antes en la zona circulaba plata en bruto y acuñaciones en ese metal procedentes del ámbito helénico ${ }^{30}$, el inicio de las acuñaciones de moneda de Arse tendría lugar durante la segunda mitad del s. IV con una emisión de óbolos con rueda de cuatro radios en el reverso que presentan semejanzas con las fraccionarias ampuritanas o los óbolos masaliotas y con unos rasgos iconográficos semejantes ${ }^{31}$, pronto seguidos por las primeras emisiones de dracmas y divisores, con rueda de seis radios en el reverso y leyenda arsesken, deudoras también de esas tipologías helénicas ${ }^{32}$ e, incluso, con algún signo en sus leyendas en el que se han visto influencias directas del alfabeto griego ${ }^{33}$. La metrología, sin embargo, no parece tener relación directa con la empleada en los centros griegos más próximos sugiriéndose su carácter autónomo para las acuñaciones más antiguas ${ }^{34}$ aunque la presencia de fraccionarias ampuritanas durante los siglos IV y III sugiere la existencia de contactos intensos con la ciudad griega ${ }^{35}$.

El inicio de las emisiones monetales coincidiría con cambios importantes en la ciudad, que de algún modo se materializarían en la construcción de una muralla $a^{36}$; ello, junto con la evidente

32 Llorens, Ripollès, 2002: 66-70; sobre la pertinencia de las denominaciones "óbolo" y "dracma", vid. Ripollès, 2002: 153-154; sobre la ordenación cronológica, Gozalbes, Ripollès, 2002: 276-277.

33 Velaza, 2002: 130; es destacable también la forma no regular de los signos de las acuñaciones más antiguas (Grupo I), interpretados hipotéticamente como ke y $\bar{r}$, aunque sin certeza absoluta; vid. Ripollès, Llorens, 2002b: 354-355; no hay propuestas satisfactorias que expliquen esta leyenda: Ripollès, 2002a: 326

34 Ripollès, 2002b: 154-157.

35 Gozalbes, Ripollès, 2002: 226-227.

36 Ripollés, 2011: 220; sobre la muralla, vid. Rouillard, 1979. 
impronta helénica de las monedas indicaría que el peso de la influencia emporitana sobre el centro de Arse está alcanzando un extraordinario nivel; es difícil obviar en este desarrollo el papel que un emporion costero pudo haber desempeñado no sólo como centro de comercio sino como introductor de intensas influencias culturales, económicas, pero sobre todo políticas, que vendrían representadas por las acuñaciones monetales, indicio de la existencia de una comunidad política con cierto desarrollo; en este sentido, el caso de Arse sería un episodio aislado en toda la costa ibérica oriental puesto que en el resto de la región las monedas tardarán en aparecer más de un siglo (Saitabi, fines del s. III a.C.) ${ }^{37}$. Por otro lado, la influencia helénica va a seguir observándose en las acuñaciones saguntinas a lo largo de todo el s. III a.C. ${ }^{38}$ llegando a aparecer, incluso, una emisión con rótulo en griego de finales del s. I a.C.inicios del s. I d.C. tal vez con un cierto afán anticuarista o "historicista" 39 . Es difícil, pues, no ver la aparición de la moneda en Sagunto como un indicio más de su inserción en redes comerciales que utilizan este medio que, en la Península, durante el s. IV, es empleado solo por los griegos; aunque sin duda había otros puntos de comercio o emporia frecuentados por griegos en las costas mediterráneas peninsulares, Sagunto debía de ser, además de uno de los más antiguos, uno de los más importantes. Una parte de los problemas a que hemos venido aludiendo en las páginas previas puede entenderse mejor si le otorgamos la importancia que merece al emporion que, como veremos después, estableció el centro ibérico de Arse en un tramo de la costa que controlaba y que, posiblemente, recibió un nombre distinto del del asentamiento principal que no fue otro que Sagunto en sus diversas formas, de las que también hablaremos ${ }^{40}$.

37 Ripollés, 2009: 74-75.

38 Llorens, Ripollès, 2002: 70-112.

39 Velaza, 2002: 128-129, 144; Beltrán, 2011: 35. La leyenda, no sin dudas, sería $\Sigma \alpha ́ \gamma($ ovviov) $\pi$ ó $\lambda(1 \varsigma)$.

40 Sobre Sagunto como emporion, Chic, 1978: 237, aunque este autor parece considerar que el mismo corresponde al asentamiento en El Castell.

41 Santiago, 1990b: 129. Añade la autora que "el núcleo urbano indígena propiamente dicho, al que haría referencia la denominación de ARSE, se asentaría más al interior de las estribaciones montañosas cercanas, mientras que en torno al
Un problema importante que plantea esta moneda es el de la duplicidad de nombres que atestiguaría ya en época romana, Arse y Sagunto cuestión que dista de estar resuelta al haber diversas interpretaciones, aunque me resulta bastante satisfactoria la que considera que "la doble denominación correspondería originariamente a dos núcleos de población diferentes, uno junto al mar y otro en la colina cercana" ${ }^{41}$, algo que hace ya tiempo sugirió García y Bellido que pensaba que podría "existir en Saguntum, además de la población ibérica, alguna colonia de griegos y latinos sita en sus cercanías, quizá a orillas del mar, que entonces estaba algo alejado (aunque menos que ahora) de la ciudad propiamente dicha" ${ }^{\prime 2}$. No parece aceptable pensar, sin embargo, que "Sagunt, a parer meu, és el nom inventat pels romans en època hellenística per designar una ciutat reconstruïda, originalmente ibèrica, el nom de la qual, Arse $=$ Ardea, va suggerir la vinculació amb la nissaga troiana" ${ }^{43}$. El topónimo Saigantha, relacionado con Sagunto (y sus variantes), es muy anterior a la época romana y certifica su uso ya desde antiguo, al menos en los ambientes griegos. Ante esa evidencia, se ha preferido dejar el asunto, en el fondo, sin resolver o con una resolución parcial, al pensar que podría darse "la posibilidad de que una población sea llamada por los iberos de una manera y por los extranjeros de otra y la posibilidad de que una población, ibérica en este caso, consienta en cambiar de nombre sin necesidad de que su demografía sea alterada sustancialmente" ${ }^{44}$. Tiene razón, sin embargo, Aranegui cuando afirma que "no hay dos ciudades diferentes en el Castell y en el Grau Vell, sino dos sectores de una misma ciudad" ${ }^{45}$, aunque resulta más difícil de aceptar que se trate de una ciudad con dos nombres pero sin que haya un desdoblamiento de los mismos para referirse a partes distintas de la misma ${ }^{46}$.

mercado portuario se habría ido constituyendo otro núcleo de población, mezclada probablemente de comerciantes indígenas y extranjeros, que seria, en mi opinión, el que los comerciantes griegos de Massalia y Emporion conocían con el nombre de $\Sigma \alpha i ́ \gamma \alpha v \theta \alpha$ y los romanos posteriormente con el nombre de Saguntum".

42 García y Bellido, 1948: II, 62.

43 Aranegui, 1988: 60.

44 Aranegui, 2004: 42-43.

45 Aranegui, 2004: 43.

46 Aranegui, 2004: 70 . 
Creo que el debate se ha desenfocado, como ocurre en otras ocasiones, por circunstancias que, en último término, descansan sobre cuestiones nominalistas. Se ha insistido en exceso sobre si estamos o no ante una dipolis, quizá en parte porque para el caso de Emporion Estrabón (III, 4,8$)$ utiliza, este mismo concepto pero no es necesario, en mi opinión, considerar que esto haya sido lo que ha ocurrido en Sagunto. Sería más fácil pensar que, como ocurre en otros lugares, el topónimo Sagunto pueda haber sido utilizado para referirse a la salida marítima de la localidad indígena, que muy bien puede haberse llamado Arse. Ejemplos de ello no faltan en otros puntos del Mediterráneo, donde ciudades como Tarquinia, Caere o la propia Roma han dispuesto de áreas portuarias con un nombre distinto al de la comunidad de la que forman parte (Gravisca, Pyrgi u Ostia, respectivamente) e incluso en la Península Ibérica esta doble toponimia, aunque ya para época romana, puede observarse, por ejemplo, Ilici-Portus Ilicitanus

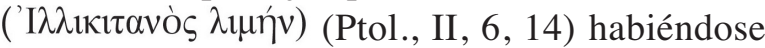
destacado el carácter empórico de este último sitio con respecto a Ilici en época ibérica ${ }^{47}$; sin duda ninguna esta denominación de "Puerto Ilicitano" que recibe el sitio en época romana pudo coexistir con la que, en su caso, le darían los habitantes locales, haya sido ésta la que haya $\operatorname{sido}^{48}$.

Así pues, no hay motivo para rechazar, $a$ priori, la posibilidad de que la escala marítima

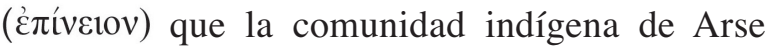
puede haber habilitado para beneficiarse de los intercambios con los navegantes mediterráneos pueda haber recibido un nombre que los griegos pueden haber interpretado como Saigantha. El que se pueda proponer esta posibilidad no significa que la misma tenga que ser cierta, por lo que se hace necesario aducir argumentos al respecto.

47 Badié et.al., 2000.

$48 \mathrm{Si}$ este sitio fue o no la Alonis que mencionan las fuentes es algo en lo que no entraremos. Vid. sobre esta cuestión, Moret 2000: 239-254. Un repaso a ésta y otras posibilidades en Abad, 2011: 20-29.

49 Contra, Aranegui, 2004: 70. Resulta también difícil que esta dualidad haya surgido solo durante época romana para referirse a dos partes del asentamiento de El Castell, una la indígena (Arse) y la otra la itálica (Sagunto) surgida entre
Sin duda, uno de los más destacables es la dualidad de nombres ya mencionada en varias ocasiones a lo largo de este trabajo y que es difícil considerar referida, al menos durante una buena parte de su historia, a un único y mismo asentamiento ${ }^{49}$; no hay motivos de peso para rechazar la posibilidad de que la Saigantha que aparece en el plomo de Ampurias pueda haber sido la transcripción, quizá fonética, al griego, de un topónimo indígena; naturalmente, lo que los griegos están nombrando es un topónimo que corresponde al lugar en el que realizan sus transacciones, esto es, un emporion, sin que sea necesario que este topónimo tenga nada que ver con el del asentamiento principal del que depende, eventualmente Arse. Ya hemos visto otros casos que muestran cómo el topónimo local, máxime si es asignado por observadores extranjeros, no prejuzga nada acerca de sus vínculos políticos. Un caso muy claro es el de Pyrgi, uno de los puertos de Caere, que recibiría su nombre griego (Пúpyot) del hecho de que allí habría torres. En cuanto a Gravisca, el puerto de Tarquinia, no sabemos el origen de su denominación que sin duda se explicaría a partir de la lengua etrusca aun cuando los romanos desarrollaron una etimología, con casi total seguridad ficticia, pero que a ellos les sirvió para justificar su nombre ${ }^{50}$. Tanto Pyrgi como Caere son llamados $\pi 0 \lambda i ́$ xvi $\alpha$ por Estrabón (V, 2, 8). Si en el caso de Sagunto hay detrás un topónimo de origen local, incluso indoeuropeo, tipo Sego- como algún autor ha sugerido, es algo que no sabemos con certeza aunque no sea improbable ${ }^{51}$; que los griegos utilizaran el nombre indígena, adaptándolo a su lengua, no plantea demasiados problemas y que, en un momento ulterior, intentaran equipararlo al de la conocida isla de de Zacinto para justificar su (ficticio) carácter helénico tampoco plantea dema-

principios del s. II a.C. y la época de César, como sugiere Aranegui, 2002a: 24-25.

50 Vid., Catón, F 50 (apud Serv., In Aen., X, 184): “ut ait Cato, ideo Graviscae dictae sunt, quod gravem aerem sustinent", aludiendo a que se trata de una zona propicia para la malaria por tener un "aire cargado".

51 Almagro Gorbea, 1979: 99-101, que habla de componente céltico; Villar, 2000: 312-313; este autor también considera que el topónimo Arse sería indoeuropeo (294), aunque no todo el mundo lo acepta: Velaza, 2002: 133. 
siados problemas ${ }^{52}$; tampoco plantearía problemas la relación Sagunto-Zacinto para los romanos si, como muestra Moralejo las primeras transcripciones al latín del nombre de la isla griega darían SACVNTO ${ }^{53}$.

Naturalmente, este lugar, Sagunto, en cuanto que entidad vinculada (o dependiente) de Arse, pero separada de la misma, debe buscarse en el actual Grau Vell. Las numerosas campañas de excavaciones llevadas a cabo en esa zona muestran que su inicio tuvo lugar a finales del s. VI a.C. con una clara vocación comercial ${ }^{54}$, esto es, de favorecer la llegada y el acceso de aquellos comerciantes que circulaban por las costas mediterráneas de Iberia y que podían hallar en ese punto de intercambio, en ese emporion, las facilidades necesarias para proceder a los intercambios. Los materiales hallados en los niveles iniciales muestran la presencia de ánforas fenicias del círculo del Estrecho y púnico-ebusitanas y de ánforas masaliotas, entre las importadas y de ánforas ibéricas de boca plana, en un porcentaje muy elevado ${ }^{55}$. Ello muestra, fuera de toda duda, la apertura a la costa del centro ibérico de Arse, en un proceso que ya tenía precedentes en otros lugares de las costas ibéricas.

Por esos mismos momentos no sólo el plomo de Ampurias atestigua los intereses comerciales de los griegos de ese otro antiguo emporion griego del golfo de Rosas en proceso de transformación en una polis sino que otros datos, como los procedentes del pecio de la Cala Sant Vicenç, en la isla de Mallorca, muestran cómo los griegos se encuentran recorriendo ya esas mismas costas y cargando en sus naves, entre otras cosas, productos envasados en ánforas ibéricas de las que han aparecido en este yacimiento ejemplares procedentes de diversos puntos de las costas peninsulares, buena parte de las cuales se atestiguan tam-

52 En efecto, el proceso no habría sido inventar de forma artificiosa una relación entre Sagunto y Zacinto a partir de relatos míticos como dan a entender algunos autores (Aranegui, 1994: 38-39) sino, por el contrario, a partir de un topónimo local, escuchado por los griegos y adaptado a su propio sistema fonético, buscar una interpretación inteligible dentro de sus habituales claves interpretativas, en las que, entre otras, la etimología juega un papel fundamental.

53 Moralejo, 2011: 295-296.

54 Aranegui, 2004: 72.

55 Aranegui, 2004: 75-76. bién en Emporion y en otros centros del sur de Francia ${ }^{56}$.

La apertura del emporion a los navegantes extranjeros, fenicios y griegos, requeriría como suele ocurrir en otros lugares, la habilitación de espacios religiosos ${ }^{57}$. Aunque las excavaciones llevadas a cabo en el Grau Vell no hayan detectado restos de establecimientos de esta índole, quizá los textos puedan ayudar en este sentido; sin duda el más relevante parece ser el de Polibio (III, 97, 6-8) que alude a que los romanos, en los prolegómenos de la conquista de Sagunto, "llegaron hasta la ciudad de Sagunto y acamparon a unos cuarenta estadios de distancia, junto al templo de Afrodita. Ocuparon un lugar muy estratégico porque les ofrecía seguridad contra el enemigo, y además era apto para que les aprovisionaran desde el mar". Desde este lugar, como se nos informa más adelante, se puede vigilar y controlar

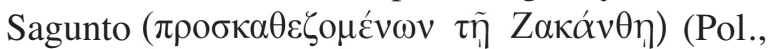
III, 98, 7). El emplazamiento de ese templo de Afrodita ha hecho correr ríos de tinta, vinculado también a la ubicación del puerto de Sagunto. Aun cuando se había venido situando dicho puerto y el santuario en la zona de Almenara aduciéndose también unos restos descubiertos en 1799 y algunos epígrafes funerarios restituidos de modo abusivo $^{58}$ ya desde el inicio de las excavaciones en el Grau Vell se ha cuestionado, con excelentes argumentos, la antigua identificación ${ }^{59}$.

La distancia que menciona Polibio entre ese templo de Afrodita y la ciudad es de cuarenta estadios, más o menos unos 7,5 km.; la distancia actual en línea recta entre el Grau Vell y Sagunto es de unos $5,5 \mathrm{~km}$. aunque si se sigue el antiguo Camí Vell del Mar que unía Sagunto con el Grau Vell, la distancia se incrementa a algo más de 6 $\mathrm{km}$. que quizá fuese alguno más en la Antigüedad teniendo en cuenta la topografía del entorno con

56 Manzano, Santos, 2008: 163-198.

57 Domínguez Monedero, 2001: 221-257.

58 Crónica de los hallazgos y planta del edificio en Chabret, 1888: II, 15-25, a quien sigue García y Bellido, 1948: II, 63-64 aunque señala que los restos publicados corresponden ya a época romana. Walbank, 1957: 432 acepta esta ubicación.

59 Aranegui, 1976: 41-46; esta autora también, desde un primer momento, sugirió la relación del templo de Afrodita con el área portuaria: Aranegui, 1988: 63-66. 
bastantes humedales en su mayor parte desaparecidos hoy día ${ }^{60}$ por los que dicho camino transita pero que antiguamente tendría que rodear. Por lo tanto, podemos pensar que, más o menos, las distancias que da Polibio coincidirían con la ubicación del Grau Vell que además sería el mejor sitio para conseguir el aprovisionamiento por mar al que también alude el autor griego. La distancia de una milla al mar que da Livio (XXI, 7, 2) para Sagunto (sita passus mille ferme a mari) es difícil de aceptar si es que Livio se está refiriendo a la ciudad situada en El Castell.

El que los visitantes extranjeros al emporio denominen con sus propios nombres a las divinidades presentes en el mismo es algo también conocido, como muestran, por ejemplo, las tablillas de oro de Pyrgi que aluden a Uni y a Astarté en los textos en etrusco y en fenicio, respectivamente, como destinataria del lugar de culto que para ella ha erigido el gobernante de Caere Thefarie Velianas ${ }^{61}$ o como muestran las inscripciones halladas en el emporion de Gravisca, donde los griegos hacen dedicatorias a sus dioses (Hera, Apolo, Afrodita, etc.) mientras que los graffiti etruscos, aunque en menor número, muestran el nombre local de algunos de esos mismos dioses, por ejemplo Turan (=Afrodita) ${ }^{62}$. También en el emporion onubense junto con la que puede ser una dedicatoria a una divinidad indígena (Nietho) ${ }^{63}$ han aparecido hace poco sendos graffi$t i$ dedicados a Hestia, Nike y Heracles ${ }^{64}$ lo que indica cómo también los griegos que realizan allí actividades han efectuado ofrendas a dioses locales (Nietho) o han llamado con nombres griegos a divinidades ya adoradas en ese lugar por las poblaciones allí residentes (ya sean indígenas o fenicios).

60 Aranegui et.al., 2005: 153-163.

61 Pallottino, 1964: 49-117; Garbini, 1989: 179-187; Colonna, 1989-90: 197-216; Serra Ridgway, 1990: 511-530; Schmitz, 1995: 559-575; Cristofani, 1996: 1117-1126.

62 Johnston, Pandolfini, 2000.

63 Fernández Jurado, Olmos, 1985: 107-113; Almagro Gorbea, 2002: $37-70$

64 García Fernández et.al., 2009: 93-103; Llompart et al., 2010: 3-14; Domínguez Monedero, 2010: 80-81.

65 Aranegui, 2004: 76-78; lecturas mejoradas en Ballester, 2006: 103-104 y Velaza, 2008: 303-304.

66 Vid. en último lugar De Hoz, 2010: 652; también, con algunos paralelos para uso comercial de estos plomos (sobre
Por consiguiente, creemos que puede aceptarse la idea de que en el área portuaria de Arse (cuyo nombre proponemos que pudo haber sido Saigantha-Sagunto) se venerase a alguna divinidad que los griegos pudieron identificar con Afrodita nombre que Polibio no tendría mayor problema en utilizar; de ser así, tendríamos otro dato más para valorar el carácter empórico del establecimiento del Grau Vell.

Otro elemento que se ha aducido para reforzar el carácter comercial del Grau Vell es el plomo hallado en 2002, datado "entre el s. V y el inicio del s. IV a.C." por el contexto arqueológico y que fue interpretado como "probable documento comercial dirigido a la población local dado el contexto en el que se halla" ${ }^{65}$, lo cual resulta bastante probable a partir de la posible adaptación por parte de los iberos de este formato ampliamente difundido por los griegos ${ }^{66}$.

También del área de Sagunto procede otro plomo, en este caso en escritura greco-ibérica, lo que resulta extraño en esta región ${ }^{67}$, hecho que hace a algún autor plantear alguna duda sobre dicha procedencia ${ }^{68}$. Al desconocerse o no haberse publicado el lugar de su hallazgo ${ }^{69}$ no puede precisarse su contexto pero, en todo caso, podría estar mostrando la participación en el comercio con Sagunto también de gentes ibéricas de la Contestania lo que avalaría el carácter abierto de su emporion durante los momentos más antiguos de su desarrollo.

A veces, se da el caso cuando se piensa en emporios, de que algunos autores consideran que los mismos son poco más que lugares donde se llevan a cabo transacciones comerciales y no consideran que puedan estar dotados de personalidad

todo la tumba II de la necrópolis de Orleyl), Aranegui, Vives-Ferrándiz, 2006: 99.

67 Fletcher, Silgo, 1991: 1-6, quienes no precisan su lugar de hallazgo más allá de un genérico "en el término municipal de Sagunto"; vid. también Pérez Vilatela, 1991: 17-58; Id., 1995: 309-339; Correa, 2008: 292.

68 De Hoz, 2010: 649; vid. sin embargo Velaza, 2002: 127 que acepta "un origen saguntino cierto".

69 Su procedencia de Sagunto sería cierta, pero no se habría hallado en "la misma orla litoral"; vid. Pérez Vilatela, 1991: 47. 
alguna y, al menos en mi opinión, estas apreciaciones no son del todo correctas. Los emporios, y las gentes que residen en ellos, que tienden a ser comunidades pluriétnicas, pueden desarrollar sus propias dinámicas y pueden verse afectados también por dinámicas generadas por otros. Según vamos saliendo de la época arcaica y entrando en el periodo clásico (por usar los parámetros cronológicos definidos para el mundo griego), la situación tiende a ir cambiando en el Mediterráneo. Los emporios se convierten en objeto de deseo por parte de algunos estados con intereses imperialistas que, por una parte, intentarán controlar aquellos que resultan de interés para ellos y que por otra tratarán de "liberar" a los que se sitúan fuera de su radio de acción. Como he argumentado en otro lugar, "por encima del equilibrio de intereses que había caracterizado a los emporios en el momento de su surgimiento (los de las autoridades indígenas, los de las poleis griegas de origen y los de los habitantes de los emporios) el final del arcaísmo ve la progresiva destrucción de esos equilibrios y, paradójicamente, con el pretexto de defender (de 'liberar' en el lenguaje de Gelón de Siracusa) esos emporios, se abrirá una larga etapa de conflictos armados en todo el Mediterráneo que dará paso a una atención mayor de los estados por los intercambios que tengan lugar en ese marco" ${ }^{70}$.

Aunque para el caso del Grau Vell de Sagunto la arqueología no muestra indicios al respecto, en otro lugar cercano, en La Picola, observamos la aparición de un recinto amurallado inspirado en prototipos griegos, que muestra cómo el área comercial y, sin duda, empórica dependiente del centro de Ilici se dota de unas estructuras defensivas que servirían para salvaguardar las actuaciones económicas llevadas a cabo en el entorno. Por otro lado, y afecte o no afecte el segundo tratado romano-cartaginés del 348 a.C. (Pol., III, 24) a la Península Ibérica ${ }^{71}$, lo que nos interesa destacar es

70 Domínguez Monedero, 2009: 127-146.

71 El debate sobre este tema es bastante amplio y no entraré de lleno en él; mientras que tradicionalmente se había aceptado sin demasiados problemas que las referencias polibianas

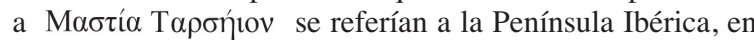
concreto a la región del Cabo de Palos (p. ej., Walbank, 1957: 347), Moret, 2002: 257-276 sugirió, con argumentos bastante sólidos en ocasiones que ese (o esos) términos deberían desvincularse de la Península Ibérica. No obstante, otros autores han argumentado en contra y vuelto a situar cómo en el mismo se establecen cláusulas restrictivas a las actividades de ambos firmantes con la finalidad de mitigar lo que cada una de las partes considera acciones piráticas llevadas a cabo por la contraria $^{72}$. Ésta será cada vez más la tendencia, a saber, arrogarse el control de los centros en los que tienen lugar las transacciones, los emporios, aunque para ello sea necesario el uso de la fuerza para impedir que los rivales utilicen la suya. Sin querer extenderme más sobre el tema, al que también le he dedicado un trabajo específico ${ }^{73}$, el ataque que Dionisio el Viejo realiza contra el emporion de Pyrgi en el 384 a.C., y de cuyo saqueo obtuvo unos beneficios de mil talentos, fue justificado por el tirano porque, según él, ese centro se había convertido en un nido de piratas (Diod., XV, 14, 3-4).

No tenemos, sin embargo, demasiados datos directos sobre cómo se vivían en los emporios estos procesos aunque los que residían en ellos tendrían sus propias posiciones y elegirían sus propios bandos y quizá eso tuviera traducción en las ventajas que recibieran. Podemos aducir un ejemplo, alejado geográficamente, pero que muestra las dinámicas propias de un emporion situado en Tracia, tal y como aparecen recogidas en un epígrafe en griego emitido por un rey tracio sucesor de Cotis I (muerto en 359 a.C.) que reconoce derechos y deberes de los habitantes del emporion; se trata de la conocida como inscripción de Pistiros ${ }^{74}$. El emporion que surge del epígrafe es "un groupe humain organisé et, en même temps, une place de commerce - groupe et place de commerce faisant partie d'un royaume barbare, nés à la suite d'une décision d'un souverain barbare, protégés, contrôlés et fiscalement exploités par celui-ci" ${ }^{75}$. Pero, no obstante, tienen una serie de privilegios y derechos, otorgados por la autoridad indígena entre ellos, dirimir los conflic-

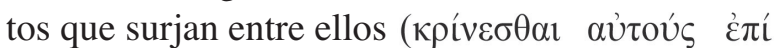

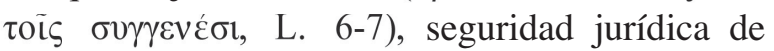

el topónimo en territorios peninsulares, aunque no en el área del cabo de Palos sino en las regiones en torno al Estrecho de Gibraltar: Ferrer Albelda, 2008: 141-156.

72 Scardigli, 1991: 89-127.

73 Domínguez Monedero (en prensa).

74 La editio princeps del texto en Velkov, Domaradzka, 1994: 1-15; lectura mejorada, teniendo en cuenta aportaciones diversas en Chankowski, Domaradzka, 1999: 247-258.

75 Bravo, Chankowski, 1999: 280; $c f$. Bresson, 1993: 163-226. 
los intercambios y compromisos del pago de deudas, estar libres de expropiaciones de las tierras y

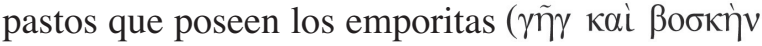

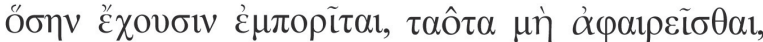
L. 10-12) e impedir que tropas móviles tracias acampen en el emporion ( $\dot{\varepsilon} \pi \alpha v \lambda ı \sigma \dot{\alpha} \varsigma \mu \grave{\eta} \pi \varepsilon \dot{\varepsilon} \mu \pi \varepsilon ı v$

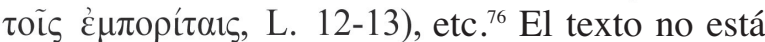
exento de problemas y de interpretaciones diversas $^{77}$ pero de este epígrafe de la segunda mitad del s. IV surge la imagen de uno o varios emporia con un cierto nivel de autonomía interna, con tierras y pastos propiedad de sus habitantes, exención de

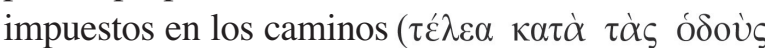

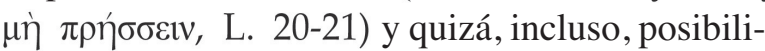
dad por parte de los emporitas de abrir y cerrar el

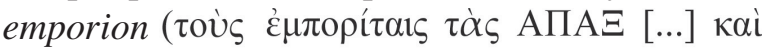

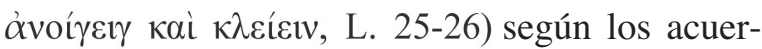
dos ya establecidos con el rey Cotis. Es posible

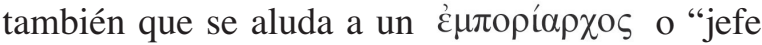
del emporio"(L. 39), aunque no es seguro al hallarse rota la piedra en ese punto pudiéndose leer solo ó ż $\mu \pi 0 \rho_{\text {...; }}$ de ser así, quizá sus funciones fue-

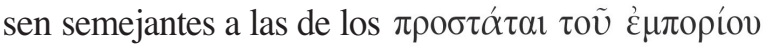
mencionados por Heródoto (II, 178) en el emporion de Náucratis.

Aunque parece haber sido un hecho aislado, los emporios no solían convertirse en poleis aunque algunos sí lo hicieron, como el emporion fundado en el golfo de Rosas que asumirá como nombre propio el genérico de Emporion ${ }^{78} \mathrm{o}$ la propia Náucratis, al menos cuando la conquista persa de Egipto modificó de forma sustancial el modelo económico y administrativo faraónico y los griegos que allí residían pudieron organizarse como polis ${ }^{79}$. Sin embargo, los datos de que disponemos, y en especial el epígrafe de Pistiros, muestran cómo los griegos tienen, a pesar de no gozar de independencia política y de soberanía, una serie de órganos internos, tierras y pastos, propiedades, derechos reconocidos que los convierten en algo más que un grupo amorfo de comerciantes extranjeros establecidos en territo-

76 Loukopoulou, 1999: 359-371.

77 Vid., de entre la amplia bibliografía, Demetriou, 2010: 77 93, que recoge todos los trabajos previos.

78 Domínguez Monedero, 2004: 164-165.

79 No todos los autores están en si Náucratis se convirtió en polis antes de la conquista de Alejandro. En contra de esa posibilidad, Bresson, 1980: 291-349; a favor de la misma, aunque en la forma de polis dependiente, Austin, 2004: 1238-1239

80 Velissaropoulos, 1977: 70-71 rios ajenos. Aunque sin duda no todos los emporios son iguales, los datos aquí considerados muestran las posibilidades que para los residentes extranjeros podían ofrecer estos lugares; todo ello, por no entrar en las prevenciones que algunos autores antiguos (por ejemplo, Platón) tienen hacia las "gentes del emporion" como potenciales responsables de peligros de diversa índole que las mismas pueden ocasionar a la ciudad que los acoge, incluyendo a las propias instituciones de la misma $^{80}$.

Todo ello nos sirve para retornar a la parte inicial de este trabajo y, al tiempo, ir concluyéndolo.

\section{5.- UNA PROPUESTA DE INTERPRETACIÓN.}

Los datos que hemos analizado al principio de nuestro trabajo nos muestran un conflicto interno en el interior de Sagunto, que se traduce en el recurso a Roma por parte de unos de los contendientes; la acción romana, de fuerza, implica la ejecución de algunos notables saguntinos que se oponen a los intereses de quienes han llamado a los romanos. Los que inician el conflicto son, si atendemos sobre todo a Apiano, los "griegos", a los que, para dotarlos de más legitimidad, se les hace "colonos" de Zacinto, asentados largo tiempo (incluso doscientos años antes de la guerra de Troya como se atreve a asegurar Plinio, XVI, 216); si a esos griegos se les añade a los procedentes de la latina Ardea ${ }^{81}$, aunque con orígenes en la Daunia (Sil.It., Pun., I, 291) se justifica mucho más la intervención romana en defensa de los "suyos". Más allá del sentido literal que los antiguos (y a veces los modernos) han dado a estos términos, hoy conocemos cómo la reflexión sobre los inicios y las tradiciones relativas a los mismos tienen siempre una lectura política que sirve a los intereses de quienes crean, difunden y amplifican esos relatos sobre los orígenes ${ }^{82}$.

$\mathrm{Y}$, sin embargo, seguramente no todo es falso en esos relatos; no es falso, por ejemplo, el carác-

81 Es interesante la sugerencia de Villar, Prósper, 2005: 222 sobre la posible semejanza fonética de la pronunciación del término ibérico Arse y el latino Ardea, que parte de la idea de que el signo ibérico $\langle s\rangle$ transcribiese la silbante africada dental.

82 Puede verse, para el caso siciliano, Sammartano, 1998: passim. Para el caso de Sagunto, vid. Coarelli 2001: 321-326 y Martínez-Pinna, 2008: 256-258, con bibliografía previa. En un sentido distinto, y buscando los posibles elementos de realidad en esas tradiciones, Barzanò, 1992: 135-143.. 
ter empórico del asentamiento portuario saguntino, como tampoco parece serlo la presencia de griegos en el mismo, quizá establecidos desde hacía tiempo (generaciones incluso) y, tal vez, la existencia de intereses compartidos entre estas gentes de origen y extracción griega y parte de los círculos dirigentes de la ciudad ibérica. Del mismo modo, también podría haber habido comerciantes itálicos, incluyendo gentes del Lacio, tal vez responsables de la distribución en las costas peninsulares (entre otros productos) de ánforas greco-itálicas y de cerámicas de barniz negro anteriores a la Segunda Guerra Púnica, y que justificarían las referencias a los orígenes latinos de Sagunto, aunque parece destacarse, de momento, el papel que ha asumido el área de Emporion/Rhode en la distribución de estos productos a otras zonas de las costas orientales de la Península Ibérica ${ }^{83}$.

Sea como fuere, la situación de Sagunto durante la segunda mitad del s. III a.C. muestra la concurrencia de intereses diversos $\mathrm{y}$, ocasionalmente, opuestos. La presencia directa de Cartago, con deseos de permanencia como muestra la fundación de Cartago Nova, tiende, como corresponde ya a la situación en esos momentos, a ejercer un control directo sobre los puntos en los que se producen los intercambios, es decir, los emporios y ello puede haberse traducido en la imposición de su dominio, bien directo bien a través de parte de las élites locales. Aunque cuestiones políticas y asuntos económicos no siempre tienen una correlación directa en el mundo antiguo, se ha señalado, en las excavaciones del Grau Vell, junto con esas producciones anfóricas y de mesa itálicas, la presencia de productos de manufactura cartagine$\mathrm{sa}^{84}$, que se ve acompañada, en otros puntos de la Península Ibérica, por la aparición, también de algunas cerámicas de ese mismo origen ${ }^{85}$; todo ello indicaría el progresivo interés de Cartago por la Península que en último término explicaría el

83 Pérez Ballester, 1994: 189-196; Cibecchini, Principal, 2002: 653-664; Domínguez Pérez, 2003: 47-59; Pérez Ballester, 2008: 263-274.

84 Aranegui, 2004: 79-81.

85 Asensio 2001-2002: 305-317.

86 Basta para hacerse una idea de la pujanza de Cartago Nova comprobar las cifras de prisioneros y de bienes allí tomados por Escipión tras la captura de la ciudad en el 209 a.C.: Pol., X, 17, 6-14; Liv., XXVI, 47, 1-3. desembarco de Amílcar y, más adelante, la fundación de Cartago Nova.

Sin duda ninguna Sagunto se ve, pues, inmersa en un mundo de intereses encontrados que, tomando como base los objetivos comerciales, tiende a proyectarse a niveles de control, económico y político. A la tradicional relación del ámbito saguntino con el comercio griego dirigido desde Emporion y al púnico dirigido desde Ibiza, a los que se va sumando con cierta timidez el comercio itálico, basado en las relaciones amistosas entre Masalia y Roma, se le añade de improviso la presencia cartaginesa. Si antes de la llegada de Cartago a Iberia Sagunto funcionó como un emporion en el que los equilibrios entre la población local y los griegos, los púnico-ebusitanos y los itálicos seguramente se respetaban, la aparición de los cartagineses y, sobre todo, la fundación de Cartago Nova provocan un cambio radical por la introducción de un nuevo componente político, sin perder de vista el demográfico ${ }^{86}$, que no podía dejar de introducir desequilibrios importantes en toda la región. Los conflictos que atestiguan las fuentes, y que llevan a la intervención romana hay que situarlos en esta perspectiva; no es improbable pensar en un escenario en el que las poblaciones vinculadas al emporion, cuyo peso político y económico no hay por qué minusvalorar, hayan intentado atraerse a la potencia rival de Cartago y que ésta, no sin vacilaciones en las que intervienen distintos factores ${ }^{87}$, se haya al final decantado por la guerra.

La imposición por parte de Roma del Tratado del Ebro es una primera señal de cómo ésta intenta coartar el expansionismo cartaginés algo que, en ese momento, Asdrúbal acepta porque, implícitamente, obtiene un reconocimiento de su política, sellado con la fundación de Cartago Nova ${ }^{88}$. Sin embargo, en ese tratado no se abordaba la situación ni de las comunidades indígenas ni de

87 Vid. un completo panorama en Wagner, 1999: 274-279; el interés económico que representa Sagunto para Cartago y para Roma ha sido subrayado por Domínguez Pérez 2005: 590-600.

88 Hoyos, 2011: 217-218 prefiere insistir en la superioridad que muestra Cartago en este tratado lo cual seguramente es cierto pero no podemos perder de vista que es Roma quien fuerza o convence a Asdrúbal para que lo firme, siendo también objeto de debate si el tratado fue ratificado o no por el senado de Cartago (Pol., III, 21, 1-5). 
los emporios situados al sur del Ebro porque ni ello tenía sentido desde un punto de vista jurídico ni Asdrúbal hubiese aceptado entonces las condiciones romanas. Como había venido siendo frecuente en otros ámbitos y en otros momentos, Cartago habría intentado establecer su control, sobre todo económico, pero también político, sobre aquellos puntos de interés comercial, entre los que se hallaba Sagunto ${ }^{89}$; no parece, sin embargo, que Cartago haya establecido ninguna área de exclusión comercial a los griegos y a sus aliados porque de haber sido así algún eco de ello habríamos tenido en las fuentes. Pero para los comerciantes que utilizaban las facilidades del emporion arsetano y para quienes residían en el mismo y ejercían su actividad en él el dominio cartaginés pudo implicar un aumento en sus tasas y sus tributos, quizá recaudados por las autoridades indígenas de las que dependía el emporion que, a su vez, trasladarían la parte correspondiente al fisco cartaginés ${ }^{90}$.

Quizá esa nueva situación fue percibida como perjudicial por los grupos más involucrados en el comercio y parece fuera de duda que los mismos buscaron apoyos en Roma tras una serie de

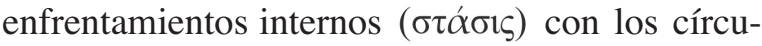
los dirigentes que serían, al menos en parte, procartagineses. La intervención de Roma se salda, como vimos, con la ejecución de una serie de notables cuya proximidad con Cartago quedaría, así, certificada; si, al tiempo, el conflicto interno surge también porque se agudizan las tensiones entre grupos oligárquicos y populares, como algún autor sugiere ${ }^{91}$, es algo que tampoco podríamos descartar. Por fin, y aunque no entra en estos detalles, Livio parece sugerir que el reforzamiento de la alianza con Roma resultó en una rápida prosperidad de Sagunto a causa del comercio marítimo y terrestre y del aumento demográfico (Liv., XXI, 7, 3: in tantas breui creuerant opes seu maritimis seu terrestribus fructibus seu multitudinis incremento) aunque el mismo también podría haber sido anterior.

89 Aunque es difícil establecer una correlación mecánica entre control político y redes de distribución comercial, en el Grau Vell parece observarse a partir de la segunda mitad del s. III la presencia de algunas producciones cerámicas manufacturadas en Cartago; vid. Aranegui, 2004: 80-81.

90 Lamentablemente, es poco lo que sabemos de los sistemas empleados por Cartago para hacer efectivo su control eco-
El resultado de este conflicto, como vimos, lo relata Polibio (III, 15, 7) aunque vuelve más adelante sobre la cuestión para, torciendo interesadamente los hechos, responsabilizar a Cartago del inicio de la guerra. Asegura el megalopolitano en esta ocasión que "cuando los saguntinos se pele-

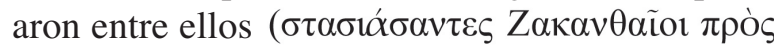
$\sigma \varphi \tilde{\alpha} \varsigma)$, no se dirigieron a los cartagineses, a pesar de que los tenían muy cerca y disponían ya de los asuntos de Iberia, sino a los romanos, y gracias a ellos enderezaron su situación política" (Pol., III, $30,2)$. Polibio insiste tras este párrafo en que, a pesar de ser los saguntinos aliados de los romanos, Cartago intervino contra ellos de forma injusta. Sin embargo, Polibio no puede dejar de reconocer (aunque lo justifique) lo extemporáneo de la intervención romana al estar el territorio bajo el control de Cartago.

Para los romanos y sus partidarios la intervención podría justificarse, como ya habían hecho otros en el pasado, como una "liberación" frente a la opresión de Cartago por más que la misma no encontrase fácil acomodo en los tratados vigentes. Por ello, la renuncia a entrar en el fondo del asunto de los embajadores romanos que, tras la caída de Sagunto en manos de Aníbal, se limitan a ofrecer a Cartago la paz y la guerra a pesar de que, en esa misma sesión, los cartagineses leyeron una y otra vez los tratados; del mismo modo, los autores prorromanos tienen que buscar diversas justificaciones para la intervención romana intentando incluir a aliados recientes en las previsiones de tratados que, como el de Lutacio Catulo, habían surgido para resolver otros problemas (p. ej., Pol., III, 29, 4-8; 30, 3-4).

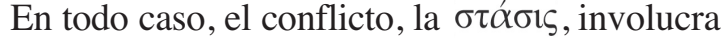
a los ciudadanos de Sagunto pero no es difícil ver en la intervención romana una justificación, quizá en un primer momento más centrada en lejanos parentescos que en cuestiones jurídicas, que sólo surgirían en el momento del estallido de la guerra entre Roma y Cartago y que serían amplificadas por los autores romanos durante y después de ella.

nómico sobre los territorios controlados de uno $\mathrm{u}$ otro modo; algunas observaciones de interés en Wagner, 1999: 286-289. Sobre la posibilidad de que los cartagineses se refiriesen a Arse-Sagunto con el nombre Qart-Alya, vid. Ferrer Maestro, 2010: 559-569.

91 Gozalbes Cravioto, 1983: 12-13. 
No hemos de minimizar la importancia que estos parentescos tenían para los antiguos, a pesar de que nuestra visión racionalista los dé de lado tildándolos de ficticios ${ }^{92}$; para los griegos que residían allí darle al emporion al que se vinculaban ( $\left.\Sigma \alpha{ }^{\prime} \gamma \alpha v \theta \alpha / Z \alpha \dot{\alpha} \kappa \alpha v \theta \alpha\right)$ un origen en la Grecia propia era un medio de reforzar su pertenencia al mundo griego. Para los romanos, aprovechar la homofonía entre Arse y Ardea significaba vincular el sitio al Lacio. Por ende, la isla de Zacinto aparece también relacionada con los orígenes legendarios de Roma al ser su fundador Zacinto hijo de Dárdano, este último antepasado también de Eneas (D.H., AR, I, 50), personaje cuya leyenda estaba en plena elaboración en los primeros historiadores romanos ${ }^{93}$ que escriben, precisamente, en estos años en los que la Segunda Guerra Púnica está en pleno apogeo ${ }^{94}$. El propio héroe Zacinto, compañero de Heracles, acabaría enterrado en la alto de la colina saguntina en el poema de Silio Itálico (Pun., I, 275); en este autor, la sangre itálica (rútula) y griega se mezclan en la figura del saguntino Murro (Pun. I, 377-379) aunque, como corresponde a un autor romano, la descendencia griega le viene por vía materna ${ }^{95}$.

En definitiva, es cierto que nos faltan datos incontrovertibles; de haberlos tenido el problema haría mucho que se habría resuelto. Sin embargo, y recapitulando lo que aquí hemos ido avanzando, creo que podemos asegurar que no estamos ante una dipolis Arse-Sagunto ni ante una colonia griega, aunque sí es bastante probable (a partir de ejemplos que hemos mostrado) que cada uno de los dos nombres se refiera a diversos entornos de una misma entidad política: la ciudad elevada y algo retirada de la costa (Arse) y el área portuaria y empórica (Sagunto). Por otro lado, y aunque sea Sagunto el nombre que perdurará en latín, y cuya relación con Zacinto será también aprovechada por los romanos, la tradición de su origen en Ardea muestra cómo éstos también trataron de vincular el sitio a sus propias tradiciones aunque

\footnotetext{
92 Curty, 1995; vid. también Erskine, 2003: 205-216.

93 Horsfall, 1987: 22.

94 Sobre éstas y otras leyendas, vid. Beltrán, 2011: 32.

95 Sobre la primacía del componente rútulo sobre el griego, vid. Bernstein, 2010: 390-395, que subraya que con eso Silio Itálico apelaba al común origen (troyano) de romanos y saguntinos; vid. también Pérez Vilatela 1990: 23-40.
}

la que acabó triunfando será la que vincula a Sagunto con un origen griego (pero sin descartar a Roma a través del mito de Dárdano, padre de Zacinto). El que triunfe en época romana una denominación (Sagunto) frente a otra (Arse) mostraría cómo tal vez Roma, que decreta la liberación y la restitución de Sagunto (Liv., XXVIII, 39, 18: Saguntum restituerint ciuesque Saguntinos seruitio exemerint), prefiere aplicar al conjunto de esa ciudad un nombre que, como Sagunto, quizá designó en un principio solo a una parte de la misma (pars pro toto) pero que fue el que propició su intervención en ella y en el conjunto de Hispania; y para la población saguntina, beneficiada por la acción romana, hacer uso de ese nombre en latín (aunque durante cierto tiempo sigan empleando en sus monedas también el de Arse) estaría en la línea de adecuarse a los deseos de los nuevos dueños del país. Como muestra la propia epigrafía saguntina, la ciudad erigió monumentos conmemorativos que resaltaban su participación en el desencadenamiento de la Segunda Guerra Púnica y de la intervención romana en Hispania (CIL, $\left.\mathrm{II}^{2}, 14,327-328\right)^{96}$; en esta situación, los arsetanos no estarían interesados en insistir demasiado ante Roma en que el nombre de su ciudad era Arse y no Sagunto que sólo designaba, inicialmente, una parte de la misma, seguramente su emporion, del mismo modo que tampoco tenían interés en recordarle a Roma que, a pesar de su (presunta) alianza, permitió que Aníbal destruyese y arrasase su ciudad y diezmase a su población sin enviar ayuda durante los ocho largos meses de asedio ${ }^{97}$.

Esta dicotomía Arse-Sagunto no implica, pues, que haya una ciudad indígena y una colonia griega, por más que los autores antiguos hayan insistido en este hecho en clave propagandística y, en último término, justificadora de la intervención romana que, a la larga, hará que estalle la guerra con Cartago. Pero, sin embargo, $\mathrm{y}$ frente a otras posturas, no puede aceptarse que

96 Beltrán, 1980: 47-50; Aranegui, 2002b: 245-254.

97 Sobre los verdaderos objetivos de Roma con esta inactividad, vid. Astin, A.E. 1967: 577-596 y, en último término, Zimmermann, 2011: 282-283. Sobre una crítica a este comportamiento en Silio Itálico, vid. Pomeroy, 2010: 59-76. 
el área portuaria no haya tenido una personalidad diversa; en ella residían extranjeros, quizá incluso a lo largo de varias generaciones, que forjan una identidad peculiar por más que no hayan tenido una personalidad política diversa ni hayan dispuesto de una soberanía propia. Sin embargo, ello no impide que hayan gozado de derechos (quizá incluso de propiedad como otros ejemplos de emporios aquí analizados muestran) y que hayan podido entablar vínculos intensos y duraderos con la población ibérica de la que dependen. Quienes rechazan esta posibilidad a cuenta de la inexistencia (por el momento) de testimonios fehacientes (por ejemplo, epigrafía arcaica) pierden de vista no sólo la escasa superficie de terreno excavada en el área del Grau Vell, en especial en sus niveles más antiguos, sino, sobre todo, la existencia de un testimonio de gran peso y valor, como la moneda a la que ya nos hemos referido y cuyo origen en Sagunto no puede explicarse sin aceptar una fuerte presencia griega que quizá sea algo más que meramente comercial al introducir nuevos comportamientos (como la acuñación de moneda) dentro de un entorno que se caracterizaría por un proceso de surgimiento de estructuras políticas que, también en la moneda emitida en nombre de la comunidad ciudadana (es decir, del estado), querían equipararse a modelos que para ellos resultaban prestigiosos como eran las poleis griegas $\mathrm{y}$, entre ellas, Emporion.

Según va pasando el tiempo y las actividades desarrolladas en el emporion arsetano van aumentando en intensidad, el mismo va generando una dinámica económica y política que acaba dejando sentir su fuerza sobre la comunidad de la que depende la cual, y no puede ser casual, acaba adquiriendo una organización política de tipo poliado, con la existencia de magistrados, senado y asamblea del pueblo (Liv., XXI, 12, 7-8; XXI, 14, 1: praetor, senatus, concilium populi) diferente de la de otros centros edetanos, incluyendo la propia Edeta ${ }^{98}$. Al final, los intereses encontrados entre distintas partes de la comunidad arsetana,

98 Guérin et.al., 1989: 198-200.

99 Domínguez Monedero, 1986: 241-258. puestos de manifiesto como consecuencia de la nueva situación creada por la fundación de Cartago Nova, van a provocar un conflicto civil en el que una de las partes, la que tenía sus intereses en el emporion arsetano, cuyo nombre posiblemente era Sagunto ( $\Sigma \alpha i ́ \gamma \alpha v \theta \alpha / Z \alpha ́ \kappa \alpha v \theta \alpha$ ) para los griegos) va a acudir a Roma, que va a intervenir de forma expeditiva en defensa de los intereses de sus comerciantes y de sus aliados. A partir de ahí, la tradición literaria conservada, unánimemente prorromana, buscará justificar dicha intervención de diferentes maneras para exonerar a Roma de la responsabilidad de haber iniciado la guerra con Cartago. Aníbal, por su parte, ya desde el inicio de su mandato, convencido de que la guerra era inevitable (a pesar de que no todos en Cartago compartían sus ideas), irá preparándose para la misma como muestran sus primeras campañas antes de abordar el sitio de Sagunto ${ }^{99}$ y el excelente pretexto que le da la vieja enemistad de la ciudad con sus vecinos los turbuletas ${ }^{100}$. Con la interpretación que hemos propuesto en este trabajo, y que dedicamos en homenaje al Profesor Manuel Bendala, no se resuelven todos los problemas pero sí, al menos, hemos tratado de integrar en un contexto histórico y arqueológico, los numerosos y con frecuencia contradictorios datos que nuestras fuentes nos han transmitido sobre el problema de Sagunto.

\section{Bibliografía}

ABAD CASAL, L. (2009): "Contestania, griegos e íberos". M. Olcina Doménech, J.J. Ramón Sánchez (eds.) Huellas griegas en la Contestania Ibérica, 20-29. Alicante.

ALMAGRO GORBEA, M. (1979): “Cerámica excisa en Sagunto. Una hipótesis sobre el origen de la ciudad”. Saguntum 14, 97-105.

ALMAGRO GORBEA, M. (2002): "Una probable divinidad tartésica identificada: Niethos/Netos". Palaeohispanica 2, 37-70.

ARANEGUI GASCÓ, C. (1976): "Las excavaciones del Grau Vell y el puerto de la ciudad de ArseSaguntum". Saitabi 26, 41-46.
${ }^{100}$ Uroz, 1982: 173-182; en las fuentes aparecen estos enemigos denominados con más frecuencia turdetanos: Pelletier, 1986: 307-314. 
ARANEGUI GASCÓ, C. (1988): “Algunes qüestions entorn de la història de Sagunt”. Fonaments 7, 57 66.

ARANEGUI GASCÓ, C. (1994): “Arse-Saguntum: una estrategia para consolidar el poder". Leyenda y arqueología de las ciudades prerromanas de la Península Ibérica, I, 31-43. Madrid.

ARANEGUI GASCÓ, C. (2002a): "Una ciudad singular”. P.P. Ripollès, M.M. Llorens (eds.) ArseSaguntum. Historia monetaria de la ciudad y su territorio, 21-30. Sagunto.

ARANEGUI GASCÓ, C. (2002b): “Ob restitutam Saguntum Bello Punico Secundo”. J.L. Jiménez Salvador, A. Ribera (eds.) Valencia y las primeras ciudades romanas de Hispania, 245-254. Valencia.

ARANEGUI GASCÓ, C. (2004): Sagunto. Oppidum, emporio y municipio romano. Barcelona.

ARANEGUI GASCÓ, C.; RUIZ PÉREZ, J.M.; CARMONA GONZALEZ, P. (2005): "El humedal del puerto de Arse-Saguntum. Estudio geomorfológico y sedimentológico". Saguntum 37, 153-163.

ARANEGUI GASCÓ, C.; VIVES-FERRÁNDIZ SÁNCHEZ, J. (2006): "Encuentros coloniales, respuestas plurales: los ibéricos antiguos de la fachada mediterránea central". M.C. Belarte, J. Sanmartí (eds.) De les comunitats locals als estats arcaics: la formació de les societats complexes a la costa del Mediterrani occidental. Homenatge a Miquel Cura, 89-102. Barcelona.

ASENSIO I VILARÓ, D. (2001-2002): “Cerámicas de cocina cartaginesas en contextos ibéricos de la costa catalana". A. González Blanco, G. Matilla, A. Egea (eds.) El mundo púnico. Religión, antropología y cultura material. Estudios Orientales 56, 305-317.

ASTIN, A.E. (1967): "Saguntum and the origins of the Second Punic War”. Latomus 26, 577-596.

AUSTIN, M. (2004): "From Syria to the Pillars of Herakles". M.H. Hansen, T.H. Nielsen (eds.) An Inventory of Archaic and Classical Poleis, 12331249. Oxford.

BADIÉ, A.; GAILLEDRAT, E.; MORET, P.; ROUILLARD, P.; SÁNCHEZ, M.J. (2000): Le site antique de La Picola à Santa Pola (Alicante, Espagne). París, Madrid.

BALLESTER, X. (2006): “Anexo. Comentario grafemático y lingüístico al plomo ibérico de Grau Vell”. M.C. Belarte, J. Sanmartí (eds.) De les comunitats locals als estats arcaics: la formació de les societats complexes a la costa del Mediterrani occidental. Homenatge a Miquel Cura, 103-104. Barcelona.
BARCELÓ, P.A. (1996): "Rom und Hispanien vor Ausbruch des 2. Punischen Krieges". Hermes 124, 45-57.

BARCELÓ, P.A. (2010): “Otra vez el tratado de Asdrúbal: Hipótesis y evidencias”. E. Ferrer Albelda (ed.) Los púnicos de Iberia: proyectos, revisiones, sintesis, I. Mainake 32.1, 407-416.

BARZANÒ, A. (1992): “La questione dell'identità zacintio-ardeate dea Saguntini: invenzione erudita, falso diplomatico o realtà storica?". M. Sordi (ed.) Autocoscienza e rappresentazione dei popoli nell'antichità, 135-143.

BECK, H. (2011): “The Reasons for War". D.B. Hoyos (ed.) A Companion to the Punic Wars, 225-241. Oxford.

BELTRÁN LLORIS, F. (1980): Epigrafía latina de Saguntum y su territorium. (Cronología. Territorium. Notas prosopográficas. Cuestiones Municipales). Valencia.

BELTRÁN LLORIS, F. (2011): "Lengua e identidad en la Hispania Romana". Palaeohispanica 11, 1959.

BENDALA GALÁN, M. (1987): "Los Cartagineses en España”. Historia General de España y América, 1.2, 115-168. Madrid.

BENDALA GALÁN, M. (2010): "La retaguardia hispana de Aníbal". E. Ferrer Albelda (ed.) Los púnicos de Iberia: proyectos, revisiones, síntesis, I. Mainake 32.1, 437-460.

BERNSTEIN, N.W., (2010): "Family and state in the PVNICA”. A. Augoustakis (ed.) Brill's Companion to Silius Italicus, 377-397. Leiden.

BRAVO, B.; CHANKOWSKI, V. (1999): "Cités et emporia dans le commerce avec les barbares à la lumière du document dit à tort 'inscription de Pistiros"”. BCH 123, 275-317.

BRESSON, A. (1980): "Rhodes, l'Hellenion et le statut de Naucratis (VIe-IVe s. av. J. C.)". DHA 6, 291-349.

BRESSON, A. (1993): "Les cités grecques et leurs emporia”. A. Bresson, P. Rouillard (eds.) L'Emporion, 163-226. París.

BRIZZI, G. (2005): “Cartagine e Roma: dall'intesa al confronto". C. Bearzot, F. Landucci, G. Zecchini (eds.) L'equilibrio internazionale dagli antichi ai moderni, 29-43. Milán.

CARCOPINO, J. (1953): "Le traité d'Hasdrubal et la responsabilité de la deuxième guerre punique". REA 55, 258-293.

CARCOPINO, J. (1960): "A propos du traité de l'Ebre". CRAI, 341-346. 
CHABRET, A. (1888): Sagunto. Su historia y sus monumentos. Barcelona.

CHANKOWSKI, V;; DOMARADZKA, L. (1999): "Réédition de l'inscription de Pistiros et problèmes d'interprétation". $B C H$ 123, 247-258.

CHIC GARCÍA, G. (1978): “La actuación políticomilitar cartaginesa en la Península Ibérica entre los años 237 y 218”. Habis 9; 233-242.

CIBECCHINI, F.; PRINCIPAL, J. (2002): “Alcune considerazioni sulla presenza commerciale romano-italica nella penisola iberica prima della seconda guerra punica". M. Khanoussi, P. Ruggeri, C. Vismara (eds.) L'Africa Romana XIV. Lo spazio marittimo del Mediterraneo occidentale: geografia storica ed economia, 653-664. Roma.

COARELLI, F. (2001): “'Origo Sagunti': l'origine mitica di Sagunto e l'alleanza con Roma". V. Fromentin, S. Gottleland (eds.) Origines gentium, 321-326. París.

COLONNA, G. (1989-90): “'Tempio’ e 'santuario’ nel lessico delle lamine di Pyrgi”. ANATHEMA. Regime delle offerte e vita dei santuari nel Mediterraneo antico. Scienze dell'Antichità. Stor.Arch.Antrop. 3-4, 197-216.

CORREA, J.A. (20089: “Crónica epigráfica del Sudeste I”. Palaeohispanica 8, 281-293.

CRISTOFANI, M. (1996): "Sulla dedica di Pyrgi". E. Acquaro (ed.) Alle soglie della classicità. Il Mediterraneo tra tradizione e innovazione (scritti in onore di S. Moscati), III, 1117-1126. Roma.

CURTY, O. (1995): Les Parentés légendaires entre cités grecques: catalogue raissoné des inscriptions contenant le terme 'syngeneia' et analyse critique. Ginebra.

DEMETRIOU, D. (2010): "Pistiros and a North Aegean Trade Network". AC 79, 77-93.

DOMÍNGUEZ MONEDERO, A.J. (1986): "La campaña de Aníbal contra los vacceos: sus objetivos y su relación con el inicio de la Segunda Guerra Púnica”. Latomus 45, 241-258

DOMÍNGUEZ MONEDERO, A.J. (2001): "La religión en el emporion”. Gerión 19, 221-257.

DOMÍNGUEZ MONEDERO, A.J. (2004): "Spain and France (including Corsica)". M.H. Hansen, T.H. Nielsen (eds.) An Inventory of Archaic and Classical Poleis,157-171. Oxford.

DOMÍNGUEZ MONEDERO, A.J. (2009): “El final del Arcaísmo y la transformación de los mecanismos de intercambio en el Mediterráneo". Gerión $27,127-146$.
DOMÍNGUEZ MONEDERO, A.J. (2010): "Fragmento de copa con inscripción griega". M.D. López de la Orden, E. García Alfonso (eds.) Cádiz y Huelva. Puertos fenicios del Atlántico, 80-81. Sevilla.

DOMÍNGUEZ MONEDERO, A.J. (en prensa): "Piratería en Magna Grecia y Sicilia: mecanismos de prevención y contención”. A. Álvarez-Ossorio, E. Ferrer, E. García (eds.) Piratería y seguridad marítima en el Mediterráneo Occidental y la Península Ibérica durante la Antigüedad. Sevilla.

DOMÍNGUEZ PÉREZ, J.C. (2003): “El barniz negro romano como argumento comercial en el horizonte prebélico contra Cartago". Salduie 3, 47-59.

DOMÍNGUEZ PÉREZ, J.C. (2005): "El potencial económico de Saiganthé como 'casus belli' en el estallido de la segunda Guerra Púnica”. Latomus 64, 590-600.

ECKSTEIN, A.M. (1984). "Rome, Saguntum and the Ebro Treaty". Emerita 52: 51-68.

ERSKINE, A. (2003): "Distant cousins and international relations: Syngeneia in the Hellenistic World". K. Buraselis, K. Zoumboulakis (eds.) The Idea of European Community in History, II. Aspects of connecting poleis and ehtne in Ancient Greece, 205-216. Atenas.

FERNÁNDEZ JURADO, J.; OLMOS, R. (1985): "Una inscripción jonia arcaica en Huelva". Lucentum 4, 107-113.

FERRER ALBELDA, E. (2008): "Notes on the Geographical Location of the Polybian Toponyms Mastia Tarseion". Rivista di Topografia Antica $18,141-156$.

FERRER MAESTRO, J.J. (2010): "Qart-Alya, el topónimo púnico de Saguntum”. E. Ferrer Albelda (ed.) Los púnicos de Iberia: proyectos, revisiones, síntesis, I. Mainake 32.1, 559-569.

FLETCHER VALLS, D.; SILGO GAUCHE, L. (1991): "Plomo ibérico, en escritura jonia, procedente de Sagunto". Arse 26, 1-6.

GARBINI, G. (1989): "L'iscrizione di Pyrgi". RstudFen 17, 179-187.

GARCÍA FERNÁNDEZ, M.; DOMÍNGUEZ, A.J.; GONZÁLEZ DE CANALES, F.; SERRANO, L.; LLOMPART, J. (2009): “Una inscripción griega arcaica hallada en El Cabezo de San Pedro (Huelva)". Spal 18, 93-103

GARCÍA Y BELLIDO, A. (1948): Hispania Graeca. Barcelona. 
GARCÍA-BELLIDO, M.P. (2000): “La relación económica entre la minería y la moneda púnicas en Iberia". M.P. García-Bellido, L. Callegarin (coords.) Los Cartagineses y la monetización del Mediterráneo Occidental. Anejos de AEA, 22, 127-144. Madrid.

GARCÍA-BELLIDO, M.P.; BLÁZQUEZ, C. (2002): Diccionario de cecas y pueblos hispánicos. I.Introducción. II.- Catálogo de cecas y pueblos. Madrid.

GELZER, M. (1933): "Römische Politik bei Fabius Pictor”. Hermes 68, 129-166.

GOZALBES CRAVIOTO, E. (1983): "La administración local en la Hispania cartaginesa según las fuentes literarias". Unidad y pluralidad en el mundo antiguo. Actas del VI Congreso Español de Estudios Clásicos, II, 7-17. Madrid.

GOZALBES, M.; RIPOLLÈS, P.P. (2002): “Circulación y dispersión”. P.P. Ripollès, M.M. Llorens (eds.) Arse-Saguntum. Historia monetaria de la ciudad y su territorio, 215-236. Sagunto.

GUÉRIN, P.; BONET, H.; MATA, C. (1989): "La deuxième guerre punique dans l'Est ibérique à travers les données archéologiques". H. Devijver, E. Lipinski (eds) Punic Wars. Studia Phoenicia, 10, 193-204. Lovaina.

HORSFALL, N.M. (1987): “The Aeneas-Legend from Homer to Virgil". J.N. Bremmer, N. Horsfall (eds.) Roman Myth and Mythography. BICS, Suppl. 52, 12-24. Londres.

HOYOS, D.B. (2003): Hannibal's Dynasty. Power and Politics in the western Mediterranean, 247-183 $B C$. Londres.

HOYOS, D.B. (2011): "Carthage in Africa and Spain, 241-218". D.B. Hoyos (ed.) A Companion to the Punic Wars, 204-222. Oxford.

DE HOZ BRAVO, J. (2010): “L'écriture gréco-ibérique et l'influence hellène sur les usages de l'écriture en Hispanie en dans le sud de la France”. H. Tréziny (ed.) Grecs et Indigènes de la Catalogne à la Mer Noire. Actes des rencontres du programme européen Ramses 2 (2006-2008), 637-657. Aix-en-Provence.

JACOB, P. (1988): “L'Ebre de Jérôme Carcopino". Gerión 6,. 187-222.

JOHNSTON, A.W.; PANDOLFINI, M. (2000): Le Iscrizioni. Gravisca. Scavi nel santuario greco, II-15. Bari.

LEVENE, D.S. (2010): Livy on the Hannibalic War. Oxford.
LLOMPART, J.; ORTA, E.M.; GARRIDO, J.P.; GONZÁLEZ DE CANALES, F. (2010): "Discusión en torno a la lectura y soporte de una inscripción griega arcaica con dedicatoria a la diosa Hi/estia hallada en Huelva". Huelva en su Historia 13, 3-14.

LLORENS, M.M.; RIPOLLÈS, P.P. (2002): "Las imágenes". P.P. Ripollès, M.M. Llorens (eds.) ArseSaguntum. Historia monetaria de la ciudad y su territorio, 63-120. Sagunto.

LÓPEZ GREGORIS, R. (1996): "La toma de Sagunto: Polibio y Fabio Píctor”. Polis 8, 207-231.

LORETO, L. (2011): "Roman Politics and Expansion, 241-219”. D.B. Hoyos (ed.) A Companion to the Punic Wars, 184-203. Oxford.

LOUKOPOULOU, L. (1999): "Sur le statut et l'importance de l'emporion de Pistiros". BCH 123, 359-371.

MANZANO VILAR, S.; SANTOS RETOLAZA, M. (2008): "El carregament d'àmfores ibèriques". X. Nieto, M. Santos (eds.) El vaixell grec arcaic de Cala Sant Vicenc. Monografies del CASC, 7, 163198. Barcelona.

MARTÍNEZ-PINNA NIETO, J. (2008): “Las tradiciones fundacionales en la Península Ibérica". P. Anello, J. Martínez-Pinna (eds.) Relaciones interculturales en el Mediterráneo antiguo: Sicilia e Iberia, 245-259. Málaga.

MORALEJO, J.L. (2011): “Mumio vuelve a Itálica (de nuevo sobre CIL I ${ }^{2}$ 630, II 1119)". ZPE 177, 289297.

MORET, P. (2000): “Un nom pour des ruines". Badié et al. 2000: 239-254.

MORET, P. (2002): "Mastia Tarseion y el problema geográfico del segundo tratado entre Cartago y Roma". Colonizadores e indígenas en la Península Ibérica. Mainake 24, 257-276.

OLCINA DOMÉNECH, M. (2002): “Lucentum”. J.L. Jiménez Salvador, A. Ribera (eds.) Valencia y las primeras ciudades romanas de Hispania, 255267. Valencia.

OLCINA DOMÉNECH, M. (2009a): "Las construcciones de la ciudad antigua". M. Olcina Doménech (ed.) Lucentum. (Tossal de Manises, Alicante). Arqueología e historia, 65-113. Alicante.

OLCINA DOMÉNECH, M. (2009b): "Evolución histórica y urbana". M. Olcina Doménech (ed.) Lucentum. (Tossal de Manises, Alicante). Arqueología e historia, 33-63. Alicante. 
OLCINA DOMÉNECH, M.; GUILABERT MAS, A.; TENDERO PORRAS, E. (2010): "Lectura púnica del Tossal de Manises (Alicante)". E. Ferrer Albelda (ed.) Los púnicos de Iberia: proyectos, revisiones, sintesis, I. Mainake 32.1, 229-249.

PALLOTTINO, M. (1964): "Scavi nel santuario etrusco di Pyrgi. Relazione preliminare della settima campagna, 1964, e scoperte de tre lamine d'oro inscritte in etrusco e in punico". ArchClass 16, 49-117.

PELLETIER, A. (1986): "Sagontins et Turdetans à la veille de la deuxième guerre punique". REA 88: 307-314

PÉREZ BALLESTER, J. (1994): “La cuestión de las importaciones itálicas al sur del Ebro anteriores a las Guerras Púnicas. A propósito de un vaso de Gnathia procedente de Ibiza". Saguntum 27, 189196.

PÉREZ BALLESTER, J. (2008): “La cerámica de barniz negro". D. Bernal, A. Ribera (eds.) Cerámicas hispanorromanas. Un estado de la cuestión, $263-$ 274. Cádiz.

PÉREZ VILATELA, L. (1990): "El origen de Sagunto en Silio Italico". Arse 25: 23-40.

PÉREZ VILATELA, L. (1991): "Plomo ibérico en escritura jónica, procedente de Sagunto, II: aspectos epigráficos, lingüísticos y culturales". Arse $26,17-58$

PÉREZ VILATELA, L. (1995): "El plomo grecoibérico de Sagunto y el matiz eolio focense". Emerita 63, 309-339.

POMEROY, A.J. (2010): “'Fides' in Silius Italicus' 'Punica'”. F. Schaffenrath (ed.) Silius Italicus, 5976. Frankfurt

RAMALLO ASENSIO, S.F.; RUIZ VALDERAS, E. (2009): "El diseño de una gran ciudad del sureste de Iberia. Qart Hadast”. S. Helas, D. Marzoli (eds.) Phönizisches und punisches Städtewesen. Iberia Archaeologica, 13, 529-544. Maguncia.

RIPOLLÈS, P.P. (2002a): "El panorama monetario". P.P. Ripollès, M.M. Llorens (eds.) ArseSaguntum. Historia monetaria de la ciudad y su territorio, 319-346. Sagunto.

RIPOLLÈS, P.P. (2002b): "Los patrones de peso de las monedas". P.P. Ripollès, M.M. Llorens (eds.) Arse-Saguntum. Historia monetaria de la ciudad y su territorio, 149-178. Sagunto.

RIPOLLÈS, P.P. (2009): "El dinero en la Contestania durante los siglos V-III a.C." M. Olcina Doménech, J.J. Ramón Sánchez (eds.) Huellas griegas en la Contestania Ibérica, 63-75. Alicante.
RIPOLLÈS, P.P. (2011): “Cuando la plata se convierte en moneda: Iberia oriental". M.P. García-Bellido, L. Callegarin, A. Jiménez (eds.) Barter, Money and Coinage in the Ancient Mediterranean (10th1st centuries BC). Anejos de AespA, 58, 213-226. Madrid

RIPOLLÈS, P.P.; LLORENS, M.M. (2002a): "La manufactura de las monedas y el volumen de acuñación”. P.P. Ripollès, M.M. Llorens (eds.) ArseSaguntum. Historia monetaria de la ciudad y su territorio, 179-213. Sagunto.

RIPOLLÈS, P.P.; LLORENS, M.M. (2002b): "Las monedas". P.P. Ripollès, M.M. Llorens (eds.) Arse-Saguntum. Historia monetaria de la ciudad y su territorio, 347-511. Sagunto.

ROUILLARD, P. (1979): Investigaciones sobre la muralla ibérica de Sagunto (Valencia). Valencia.

RUIZ VALDERAS, E. (2011): "De Qart Hadast a Carthago Noua: apuntes para una síntesis". J.M. Noguera, M.J. Madrid (eds.) Arx Hasdrubalis. La ciudad reencontrada. Arqueología en el Cerro del Molinete, Cartagena, 50-58. Murcia.

SAMMARTANO, R. (1998): Origines gentium Siciliae: Ellanico, Antioco, Tucidide. Roma.

SANCHO ROYO, A. (1976): "En torno al Tratado del Ebro entre Roma y Asdrúbal”. Habis 7, 75-110.

SANMARTÍ GREGO, E.; SANTIAGO ÁLVAREZ, R.A. (1987): "Une lettre grecque sur plomb trouvée a Emporion. (Fouilles 1985)". ZPE 68, 119127.

SANTIAGO ÁLVAREZ, R.A. (1990a): "Encore une fois sur la lettre sur plomb d'Emporion". ZPE 80, 79-80.

SANTIAGO ÁLVAREZ, R.A. (1990b): "En torno a los nombres antiguos de Sagunto". Saguntum 23, 123-140.

SANTIAGO ÁLVAREZ, R.A.; SANMARTÍ GREGO, E. (1988): "Notes additionelles sur la lettre sur plomb d'Emporion". ZPE 72, 100-102.

SCARDIGLI, B. (1991): I trattati RomanoCartaginesi. Pisa.

SCHMITZ, P.C. (1995): "The Phoenician text from the etruscan sanctuary at Pyrgi". JAOS 115, 559-575.

SERRA RIDGWAY, F.R. (1990): "Etruscans, Greeks, Carthaginians: the Sanctuary at Pyrgi". J.P. Descoeudres (ed.). Greek Colonists and native populations, 511-530. Oxford.

SERRATI, J. (2006): "Neptune's altars: The treaties between Rome and Carthage (509-226 B.C.)". CQ 56, 113-134.

SUMNER, G.V. (1968): "Roman Policy in Spain before the Hannibalic War". HSPh 72, 205-246. 
UROZ SÁEZ, J. (1982): “¿Turbuletas o turdetanos, en la guerra de Sagunto?”. Lucentum 1, 173-182.

VELAZA, J. (2002): "Las inscripciones monetales". P.P. Ripollès, M.M. Llorens (eds.) ArseSaguntum. Historia monetaria de la ciudad y su territorio, 121-148. Sagunto.

VELAZA, J. (2008): “Chronica Epigraphica Iberica VIII (2006)”. Palaeohispanica 8, 301-312.

VELISSAROPOULOS, J. (1977): “Le monde de l'emporion". DHA 3, 61-85.

VELKOV, V.; DOMARADZKA, L. (1994): “Kotys I (383/2-359) et l'emporion de Pistiros en Thrace". BCH 118, 1-15.

VILLAR, F. (2000): Indoeuropeos y no indoeuropeos en la Hispania Prerromana. Salamanca.

VILLAR, F.; PRÓSPER, B. (2005): Vascos, celtas e indoeuropeos. Genes y lenguas. Salamanca.
WAGNER, C.G. (1984): "Sagunto y la cuestión de las responsabilidades". Hannibal Pyrenaeum Transgreditur. XXII Centenari del pas d'Annibal pel Pirineu. 218 a. J.C.-1982 d. J.C. 5 Col.loqui Internacional d'Arqueologia de Puigcerdà, 189195. Puigcerdà.

WAGNER, C.G. (1999): "Los Bárquidas y la conquista de la Península Ibérica”. Gerión 17: 263294.

WALBANK, F.W. (1957): A Historical commentary on Polybius. Vol. I. Oxford.

ZIMMERMANN, K. (2011): "Roman Stragegy and Aims in the Second Punic War". D.B. Hoyos (ed.) A Companion to the Punic Wars, 280-298. Oxford. 
